


\section{Coastal monitoring using UAS to track changes in beach morphology: Waikīkī, Hawai'i}

Kristian McDonald, Chip Fletcher,

Tiffany Anderson, \& Korey Wong

University of Hawai'i at Mānoa

Department of Earth Sciences

Coastal Geology Group 
$v^{6}+1=$

2) $=10$

I

? nas

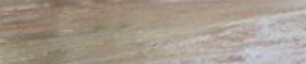

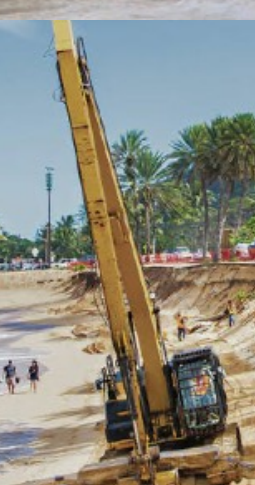

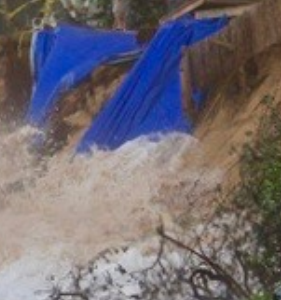

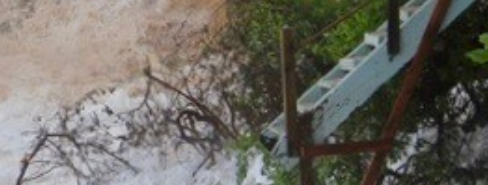

L2 $3 \mathrm{H}^{2}$

3.
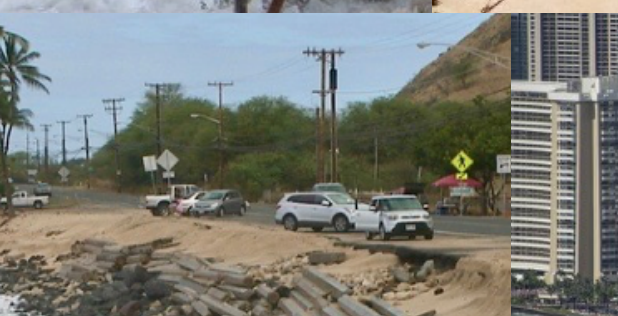

tine

-
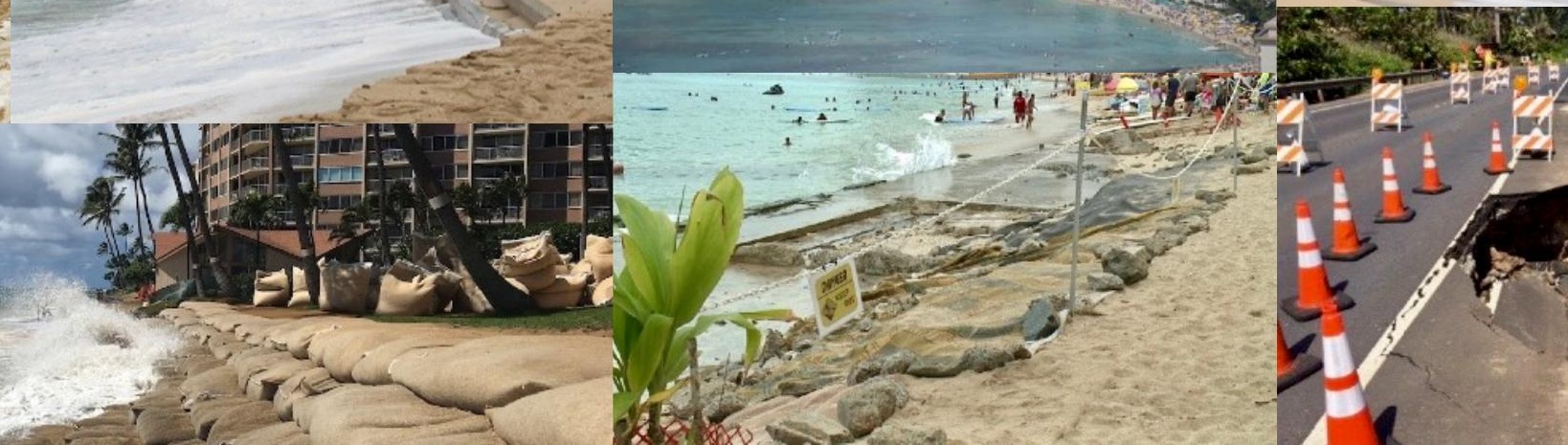

.

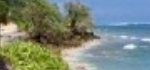


$70 \%$ of beaches on $O^{\prime}$ ahu, Maui, and Kaua'i are chronically eroding ${ }^{1}$ Hawai'i's coastal erosion is expected to double by mid-century ${ }^{2}$

1 Romine, Bradley M., and Charles H. Fletcher. "A summary of historical shoreline changes on beaches of Kauai, Oahu, and Maui, Hawaii." Journal of Coastal Research 29.3 (2012): 605-614. 
$70 \%$ of beaches on $O$ 'ahu, Maui, and Kaua'i are chronically eroding ${ }^{1}$ Hawai'i's coastal erosion is expected to double by mid-century ${ }^{2}$
A need for cost-efficient tools for effective, empirically-based coastal management 

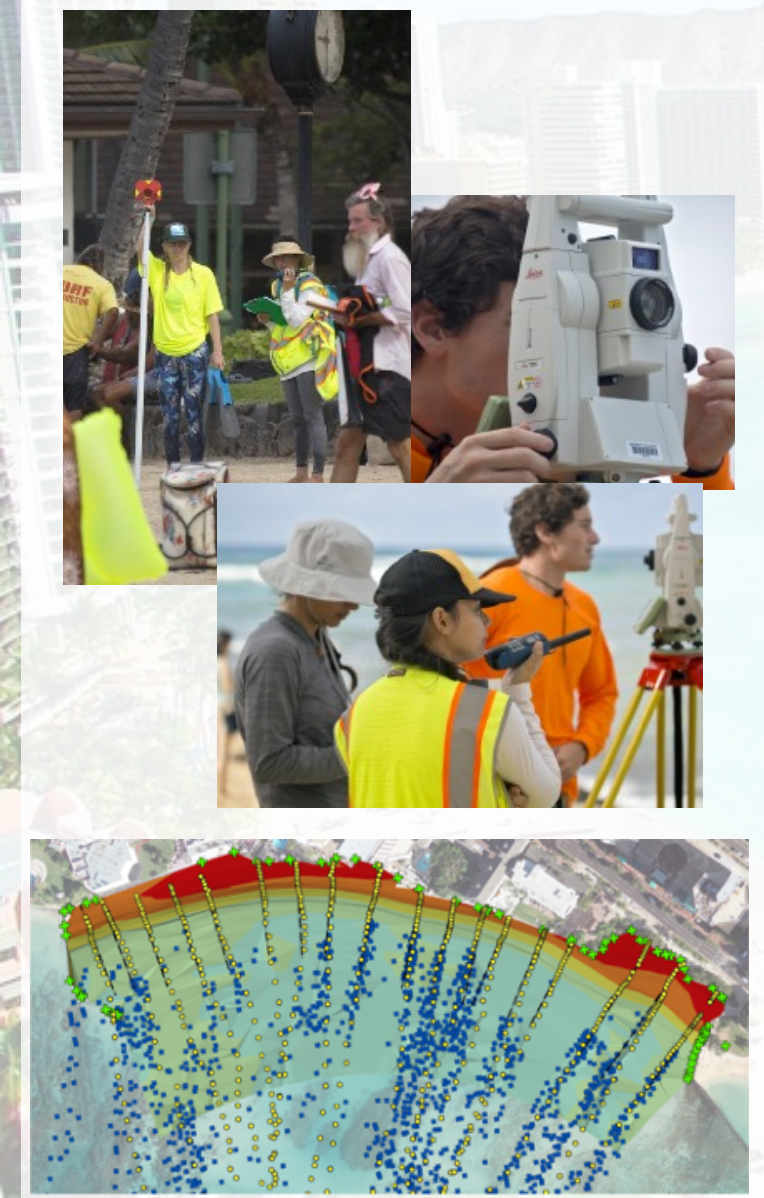

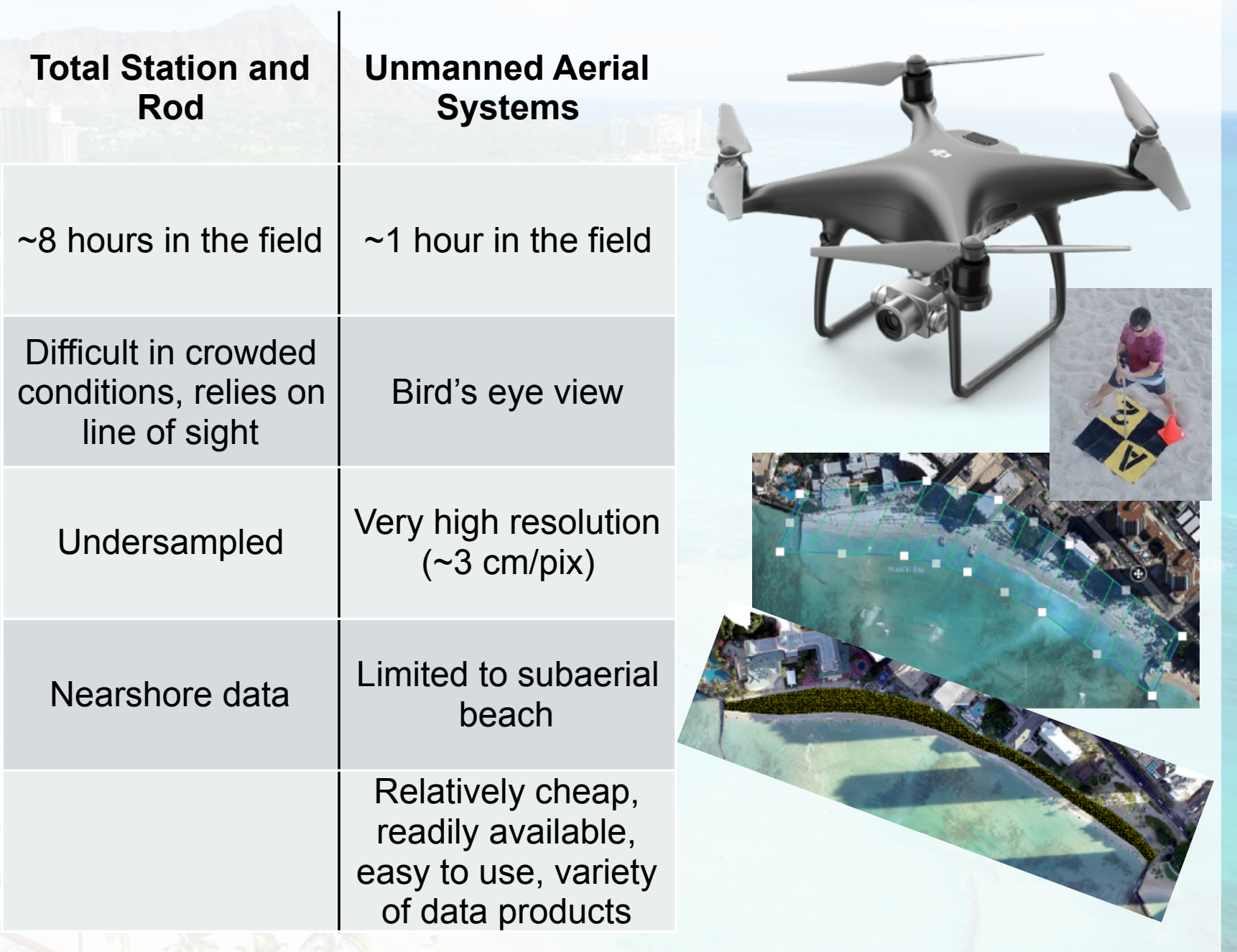




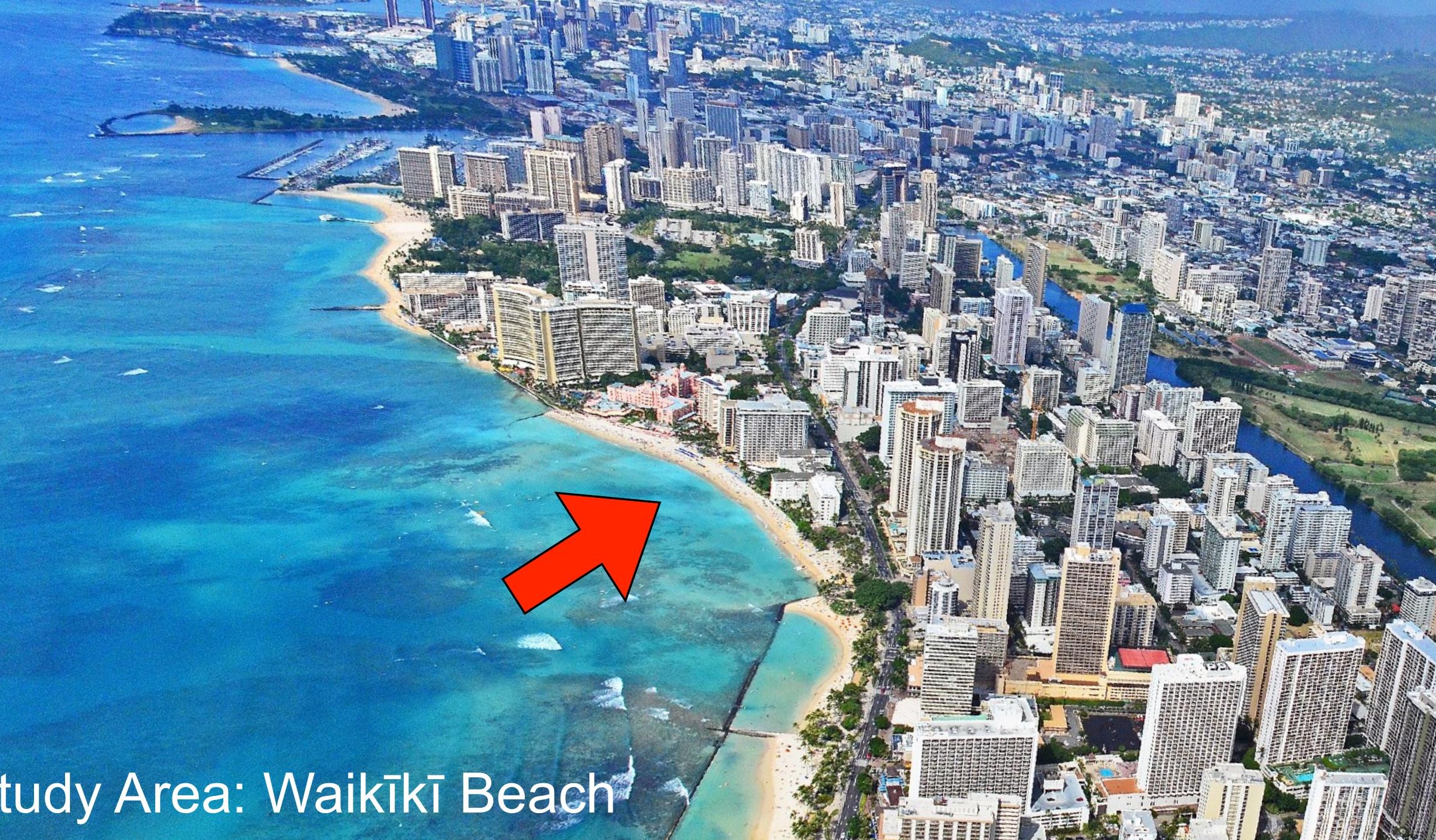




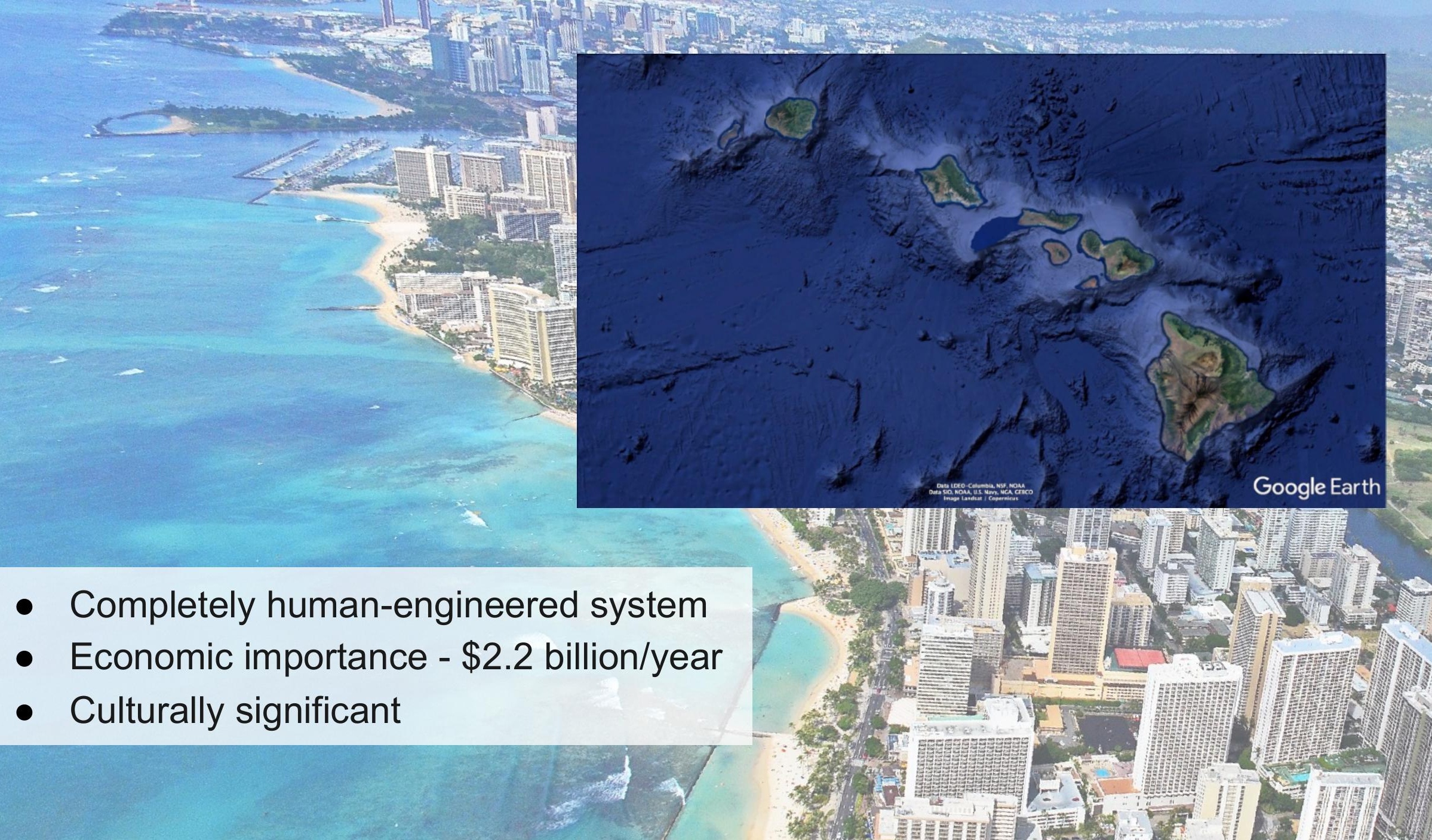




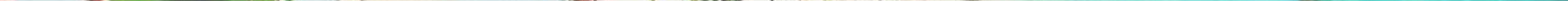




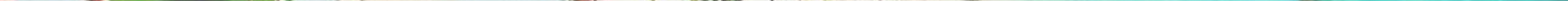




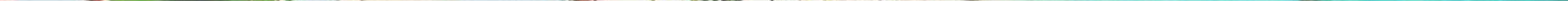




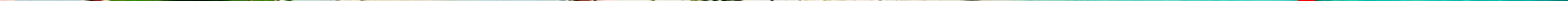


Data Collection $=-\rightarrow$ Post-Processing $=-\cdots$ Data Analysis
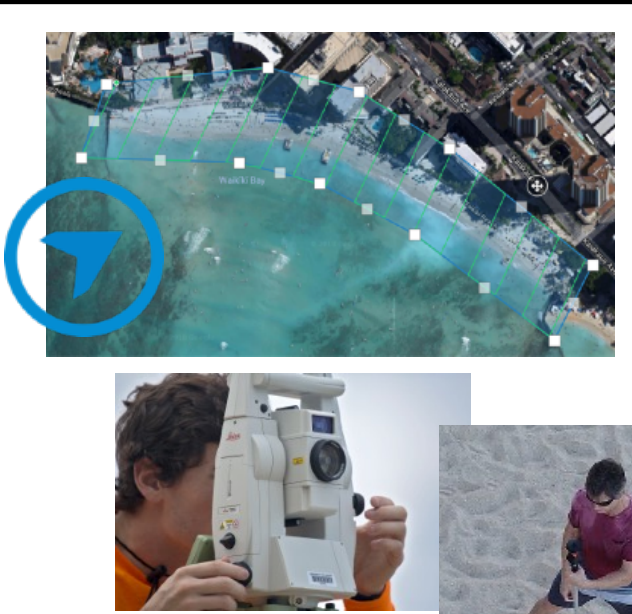

- Flight plan

- Aerial survey

- Ground survey

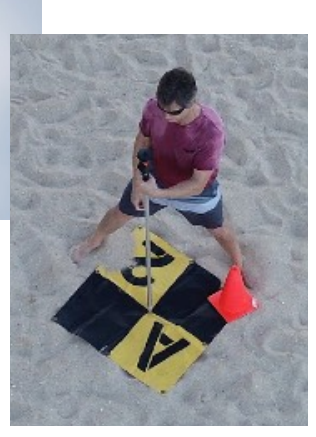

$\Lambda^{\text {Berm }}$
- Error reduction

- Point cloud and orthomosaic

generation

- Noise reduction

- "Bare earth"

extraction

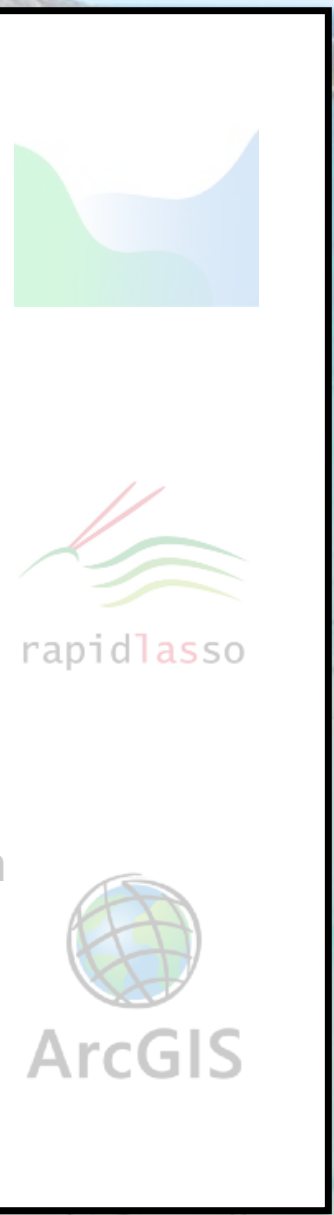

- Digital elevation model (DEM)

- Masking, smoothing, organizing
Surface area and volume analysis (broader beach response)

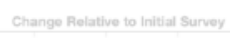

Empirical

Orthogonal Function analysis (sediment transport processes) 
- Error reduction

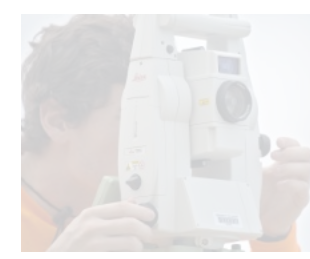

- Flight plan

- Aerial survey

- Ground survey

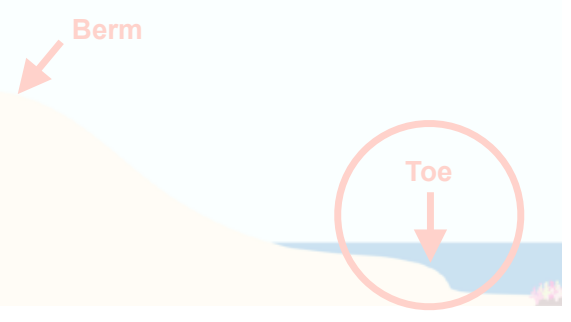

- Point cloud and orthomosaic generation
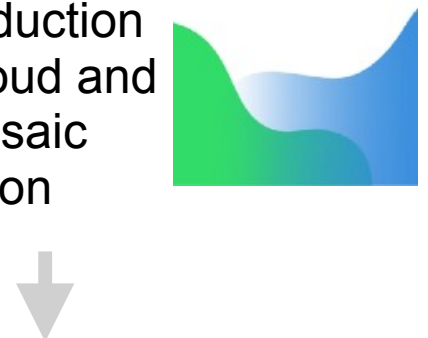

- Noise reduction

- "Bare earth"

extraction

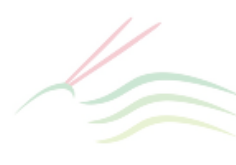

rapidlasso

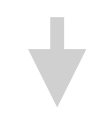

- Digital elevation model (DEM)

- Masking, smoothing, organizing
Data Analysis

- Surface area and volume analysis (broader beach response)

Change Relativo to Inital Survey

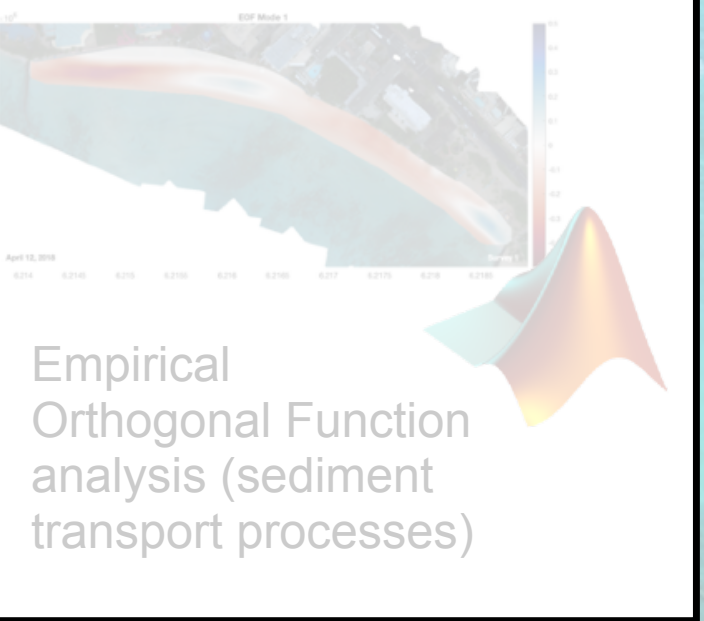




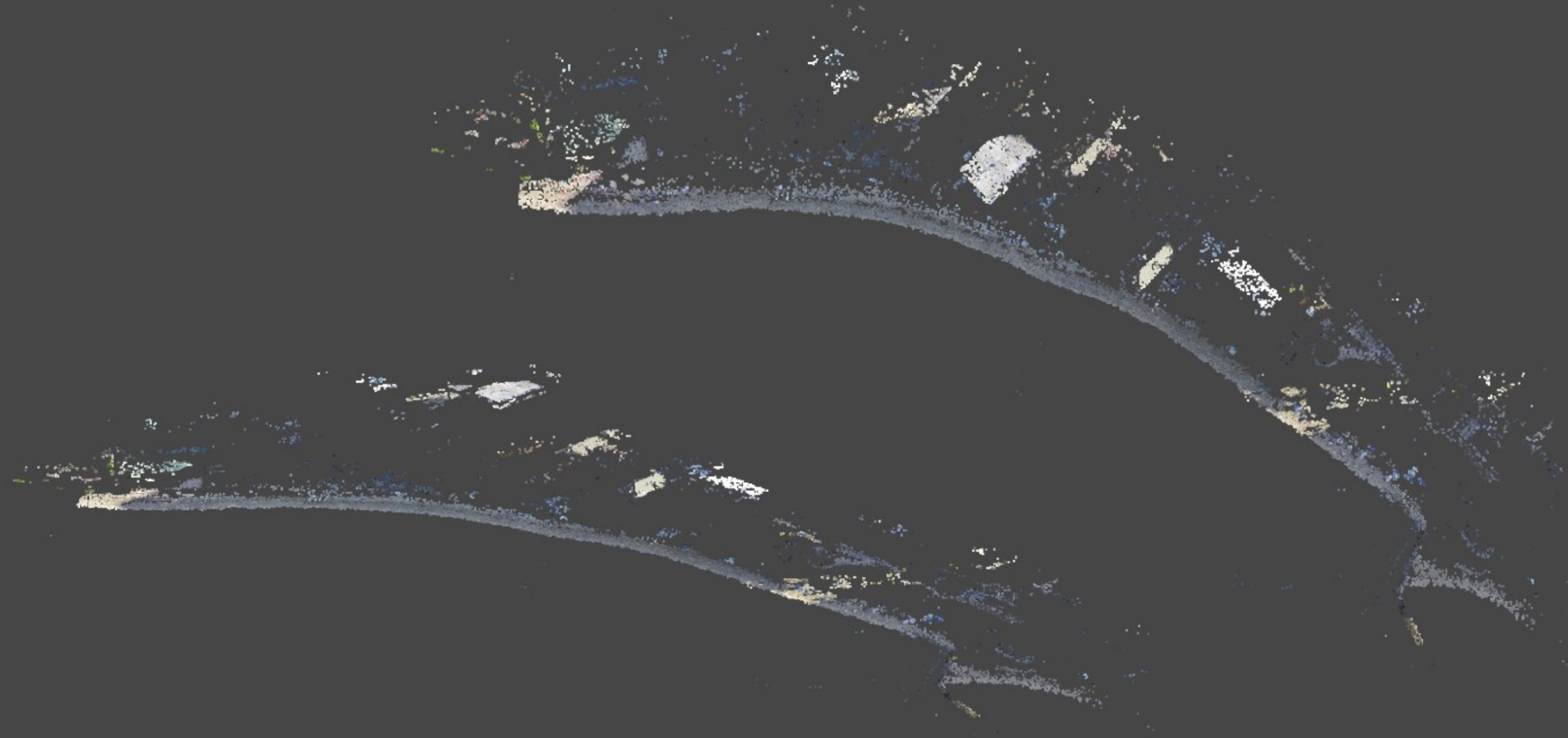

Sparse Cloud - Rudimentary 3-D model based off of common points across photos 


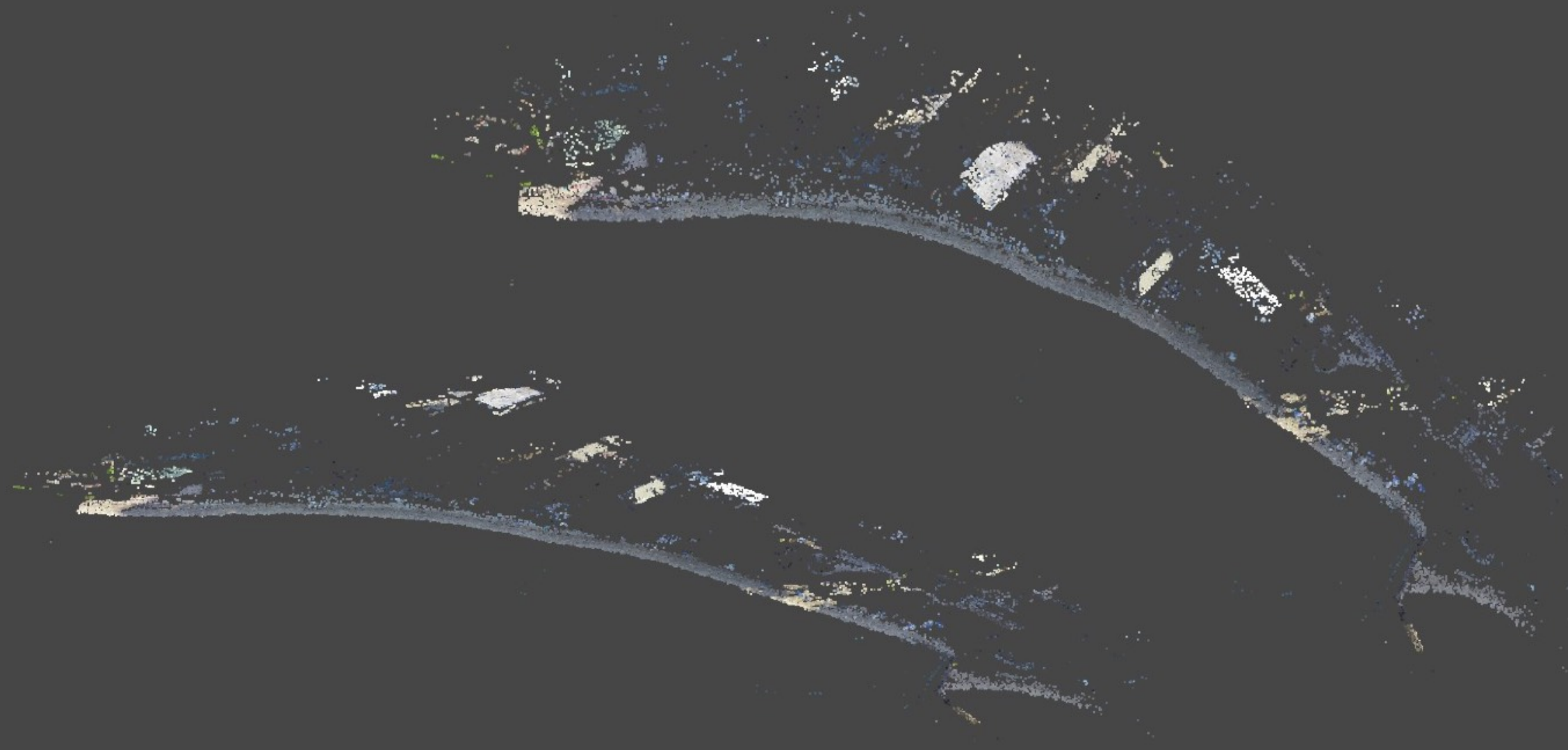

Iterative error analysis to delete the worst of the points based on uncertainty parameters 


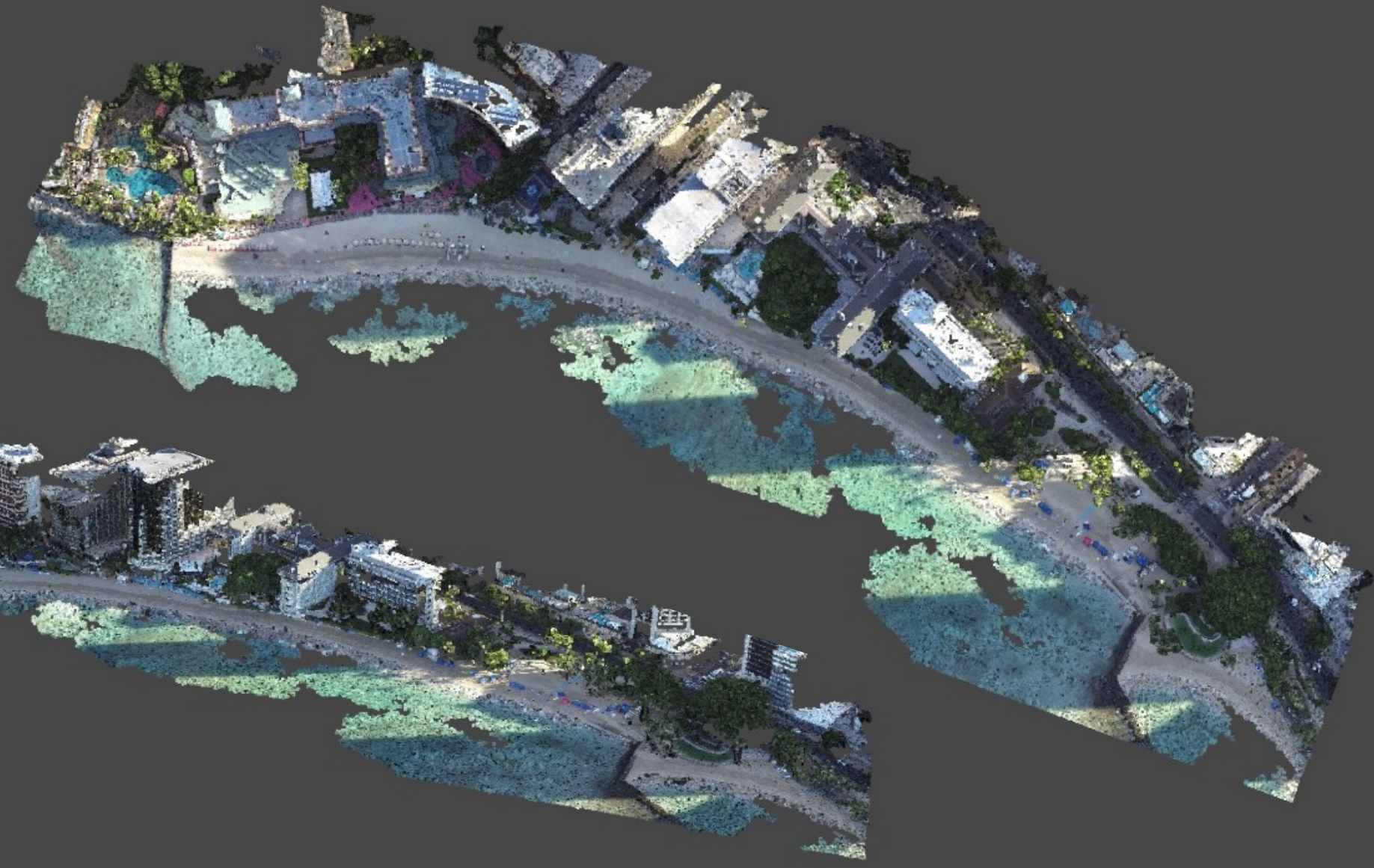

Dense Cloud - Robust point cloud based off most accurate points of the sparse cloud 


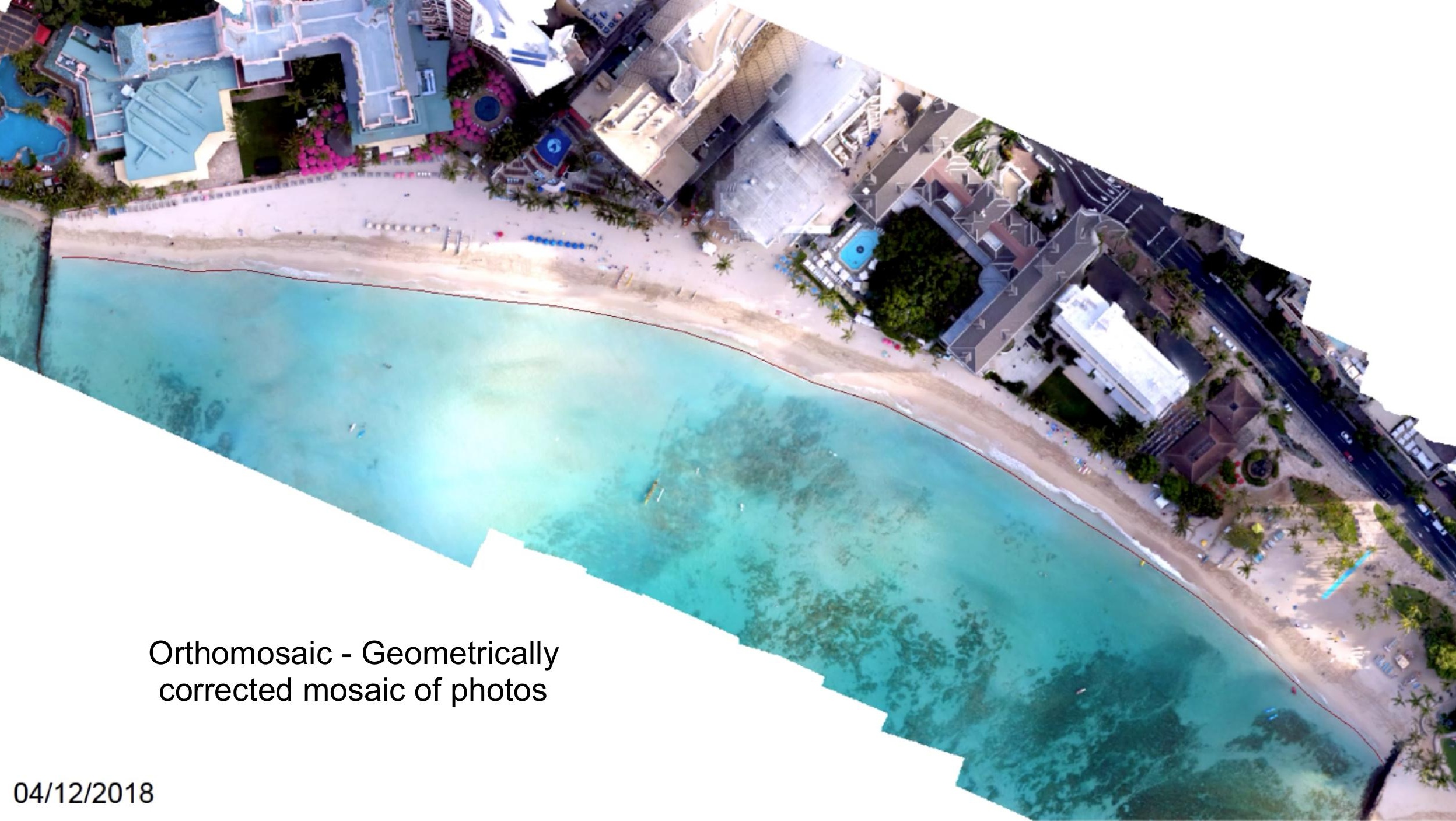




\section{Post-Processing}

- Error reduction

- Point cloud and orthomosaic generation

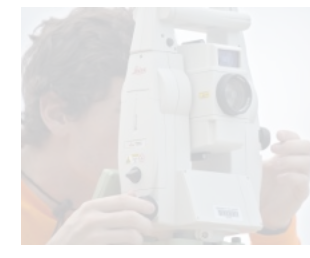

- Flight plan

- Aerial survey

- Ground survey

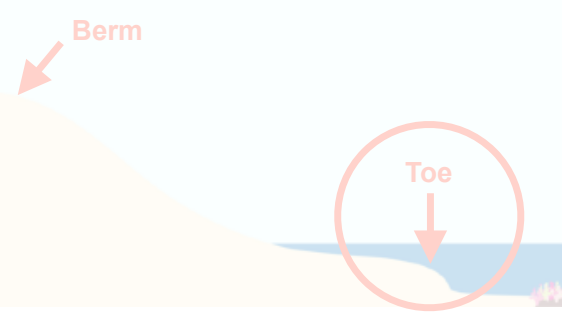

- Noise reduction

- "Bare earth" extraction

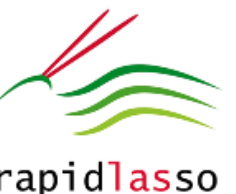

- Digital elevation model (DEM)

- Masking, smoothing, organizing

rapidlasso

\section{- - - $\rightarrow$ Data Analysis}

- Surface area and volume analysis (broader beach response)
- Empirical

Orthogonal Function analysis (sediment transport processes) 


\section{Dense Cloud Processing: LAStools}

- Stable structures on the beach require removal
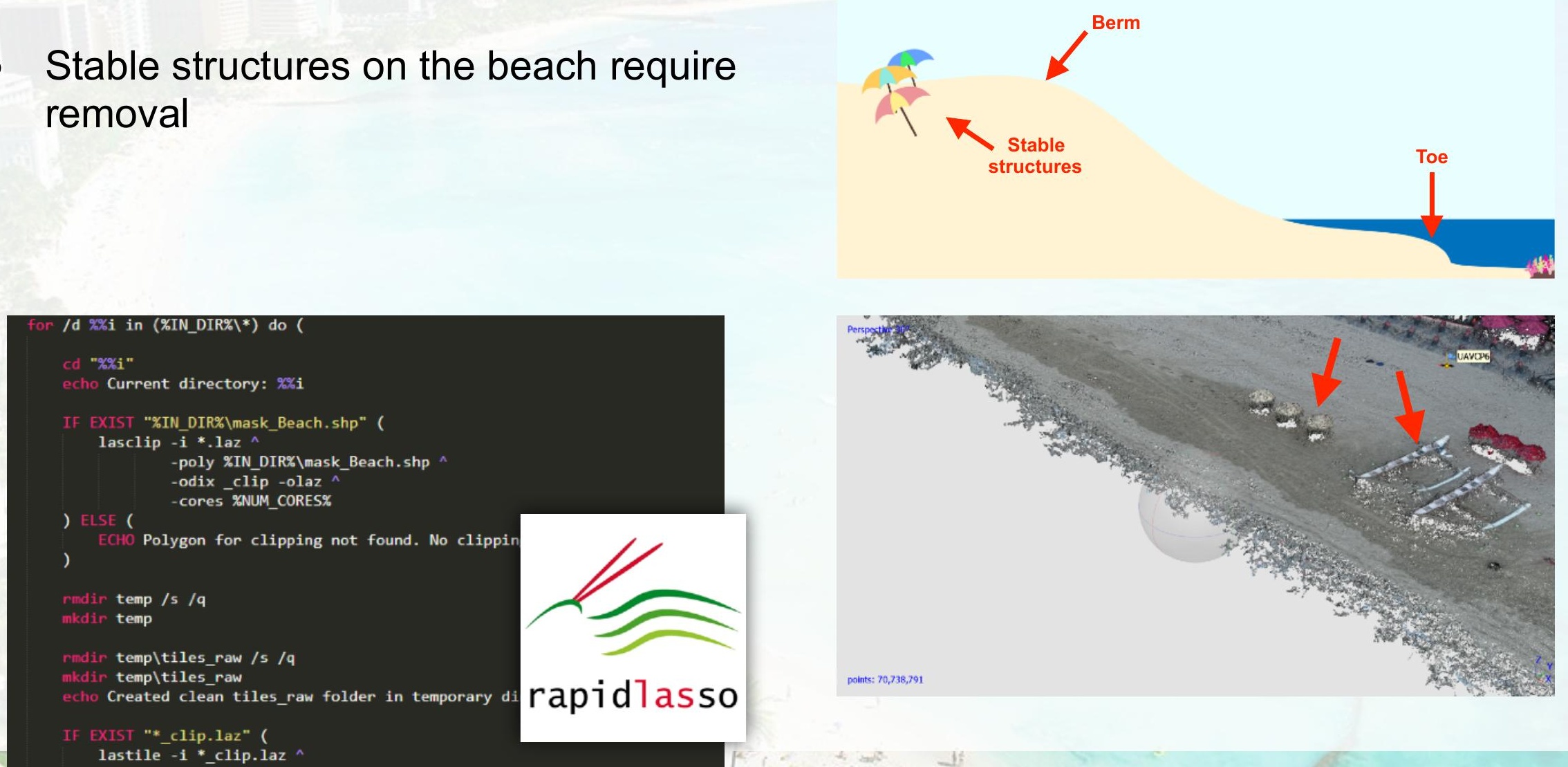


\section{Dense Cloud Processing: LAStools}

- Stable structures on the beach require removal

- Wave run-up at the foreshore results in noise - unable to resolve surface due to movement
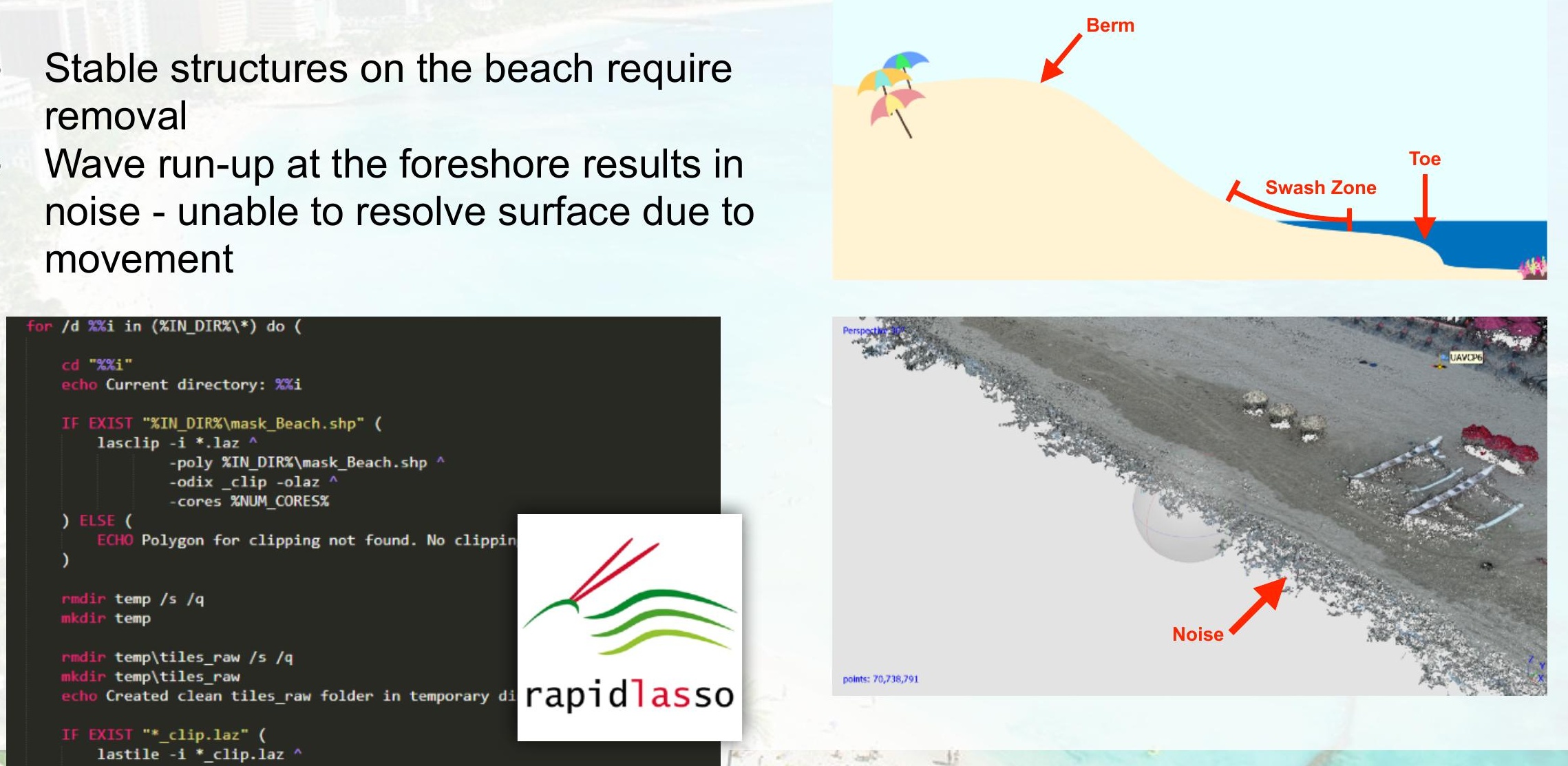


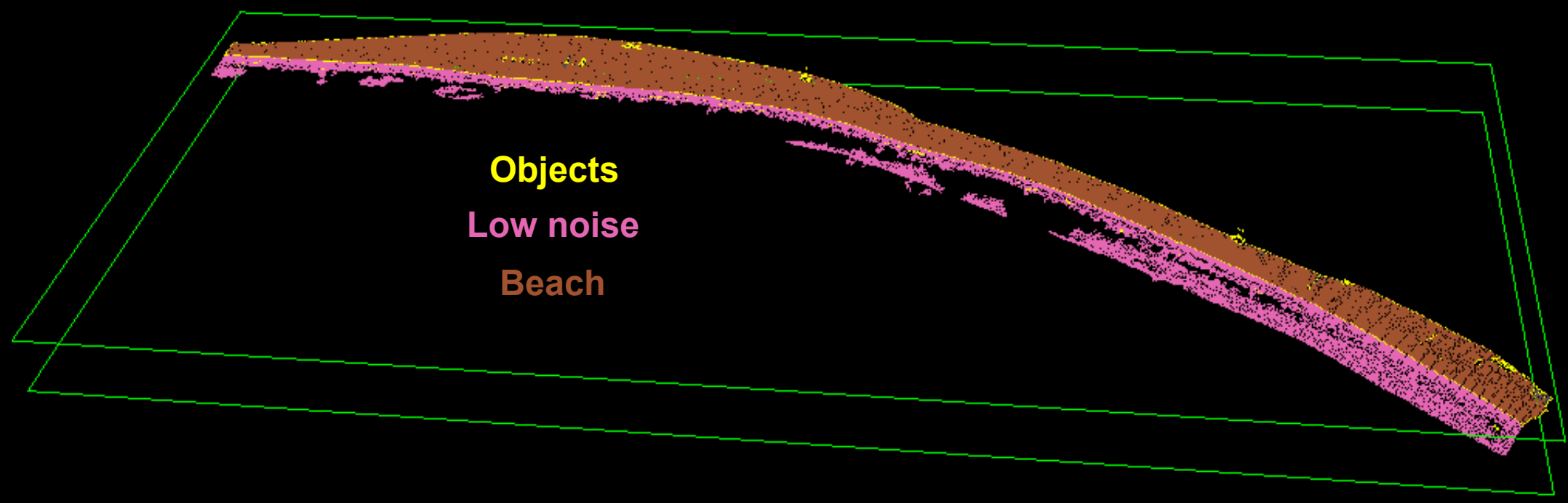

- 


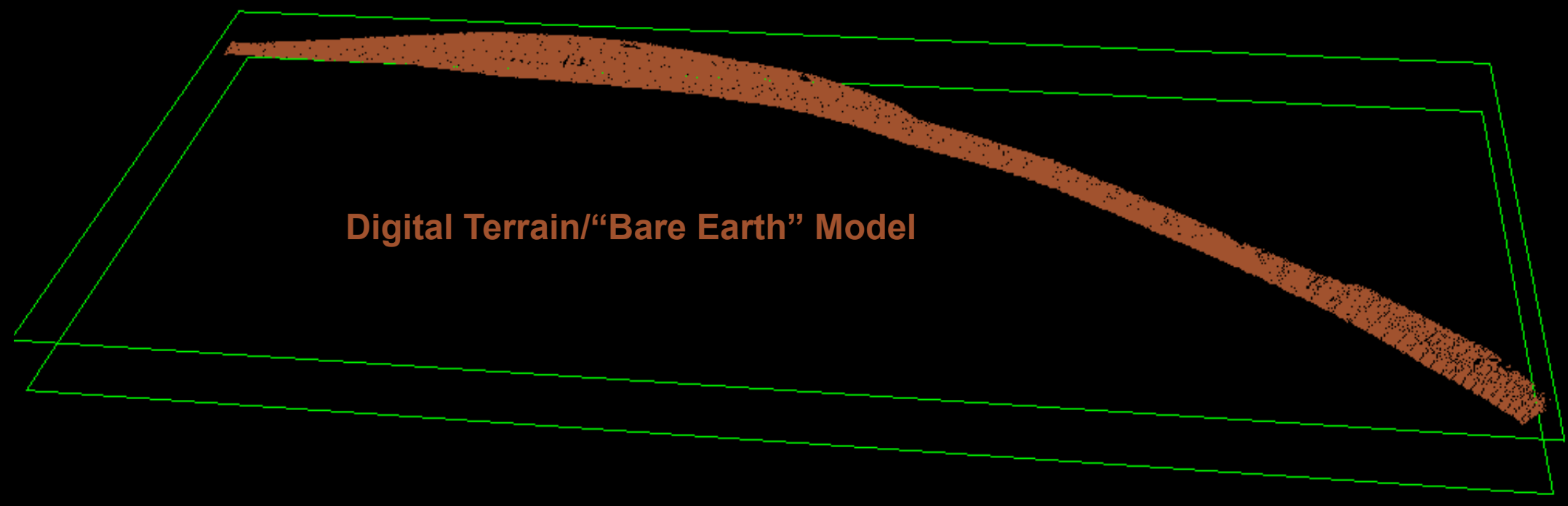


Post-Processing

- Error reduction

- Point cloud and

orthomosaic

generation

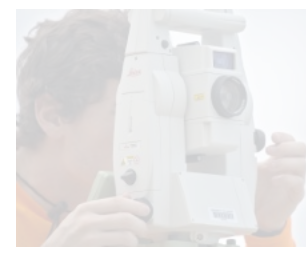

- Flight plan

- Aerial survey

- Ground survey

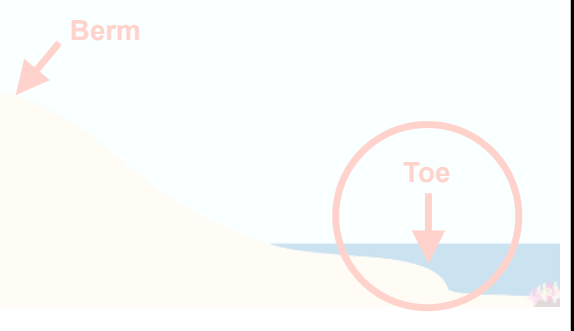

- "Bare earth"

extraction

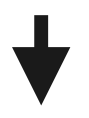

- Digital elevation model (DEM)

- Masking, smoothing, organizing
Data Analysis

- Surface area and volume analysis (broader beach response)

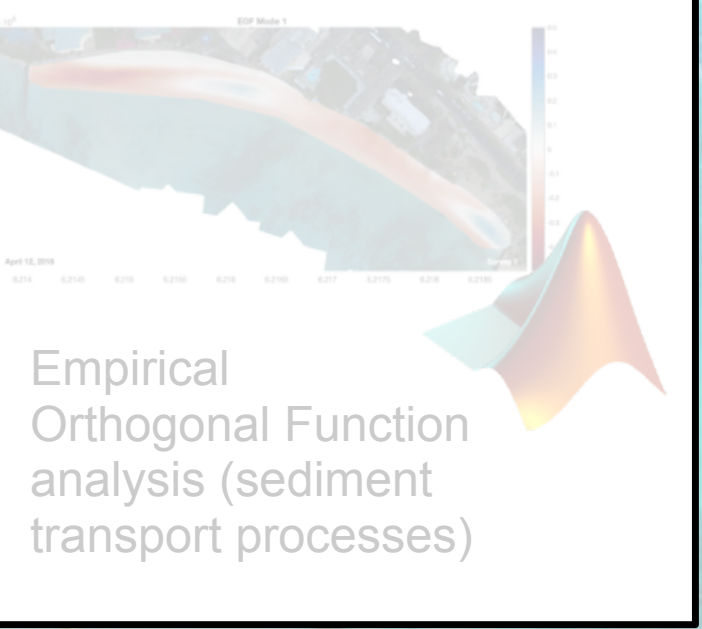




\section{Post-Processing}

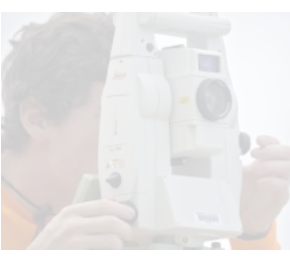

\section{Flight plan}

- Aerial survey

- Ground survey
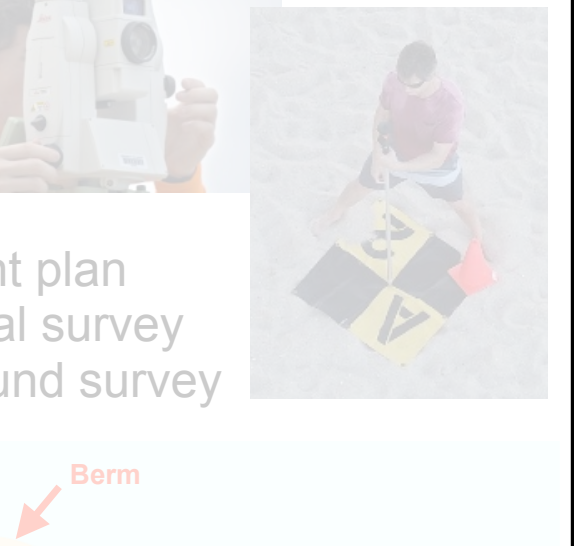

- Error reduction

- Point cloud and

orthomosaic

generation

- Noise reduction

- "Bare earth" extraction

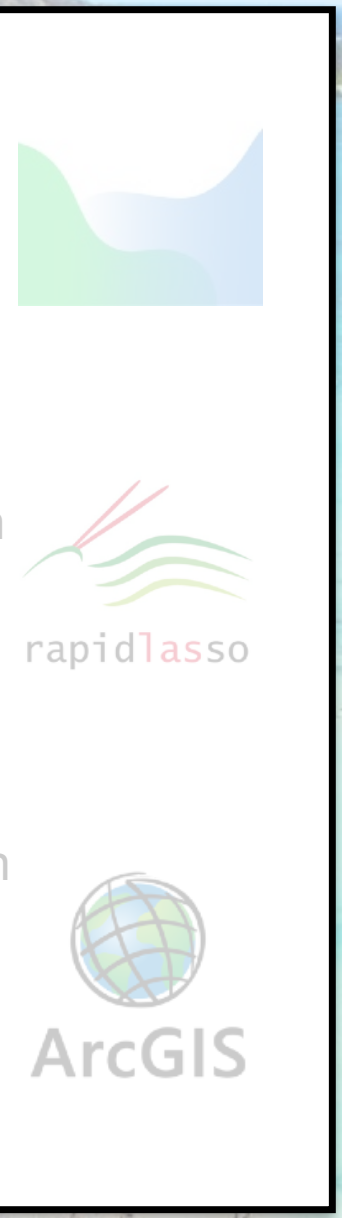

Data Analysis

- Surface area and volume analysis (broader beach response)
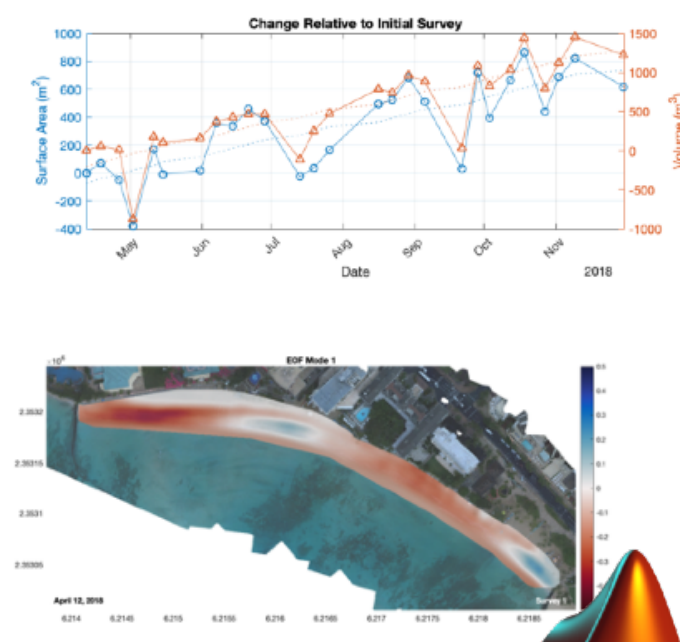

- Empirical

Orthogonal Function analysis (sediment transport processes) 


\section{Results \& Discussion}

- Correlate variations in surface area and volume with conditions

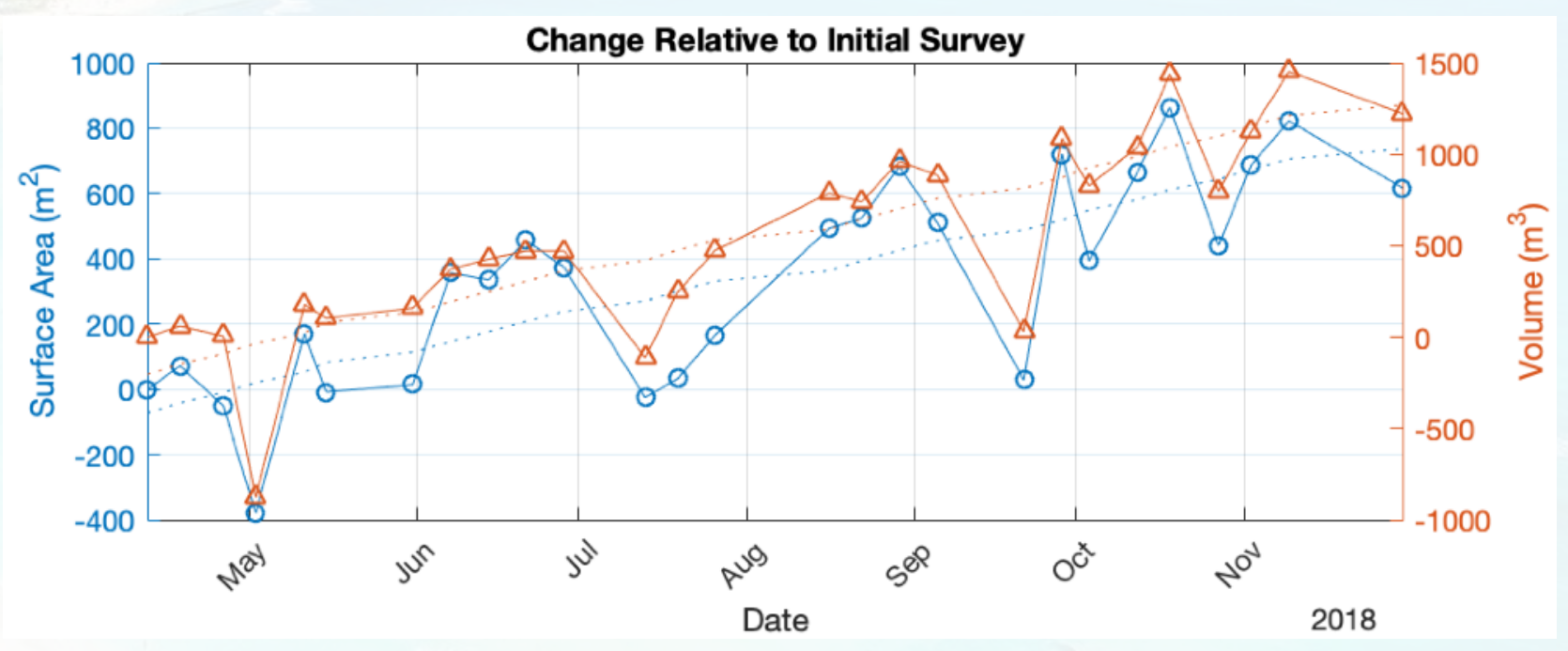




\section{Results \& Discussion}

- Correlate variations in surface area and volume with conditions

- Overall increase in both surface area and volume

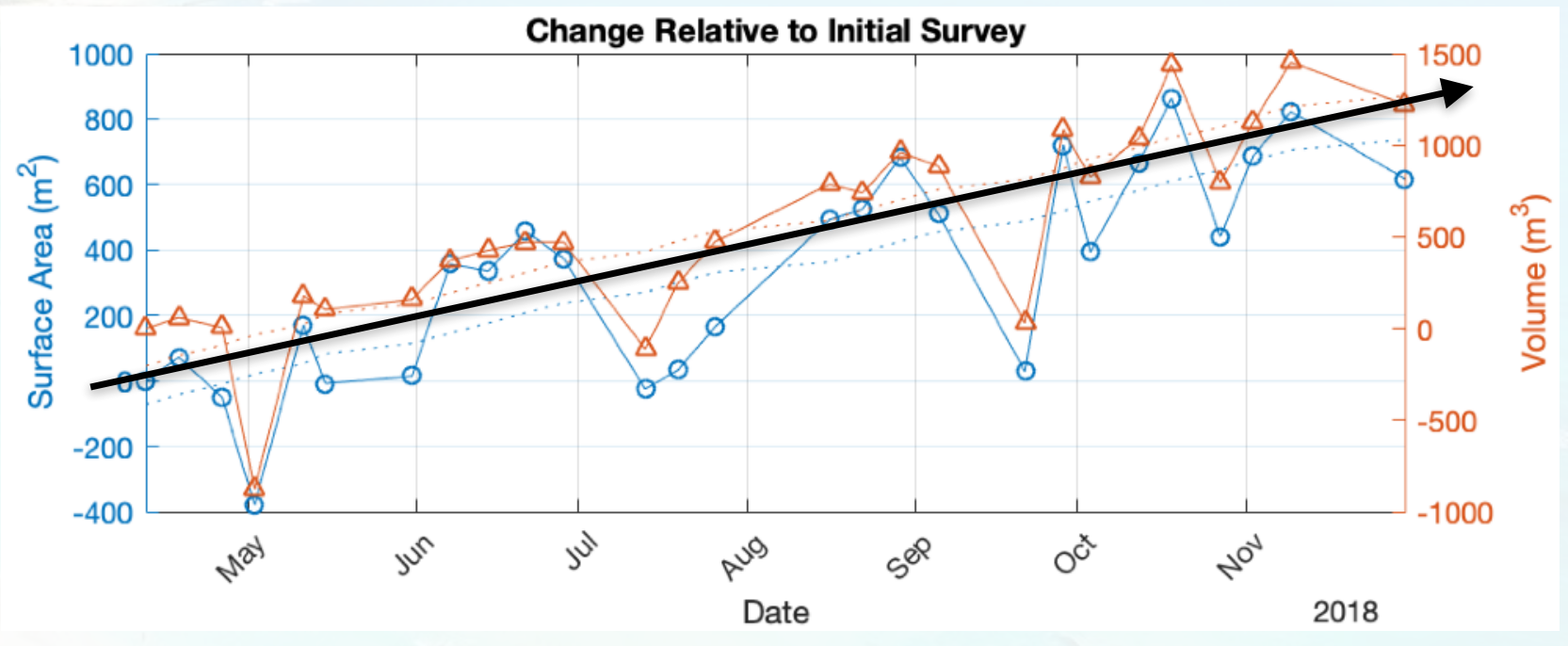




\section{Results \& Discussion}

- Correlate variations in surface area and volume with conditions

- Overall increase in both surface area and volume

- Several erosion/recovery events

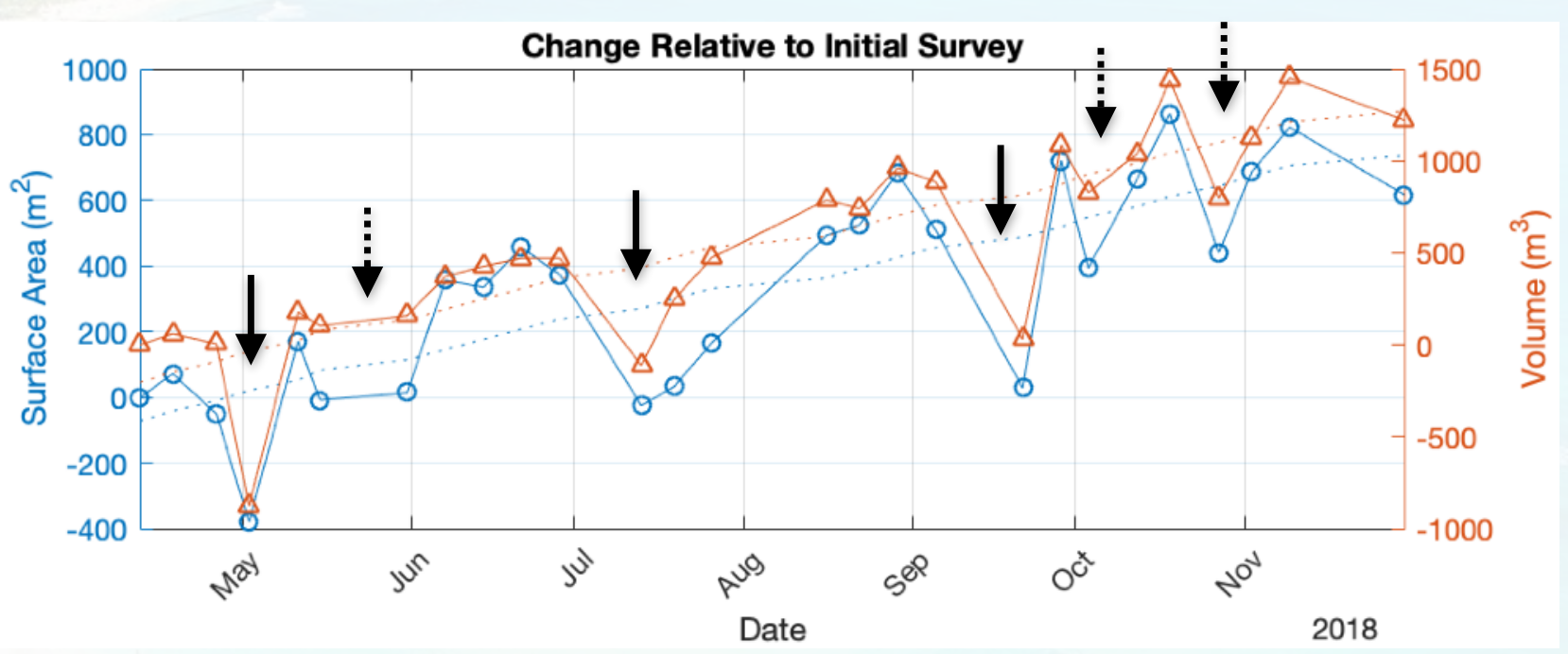




\section{Results \& Discussion}

- Correlate variations in surface area and volume with conditions

- Overall increase in both surface area and volume

- Several erosion/recovery events

- Beach volume behavior relative to surface area

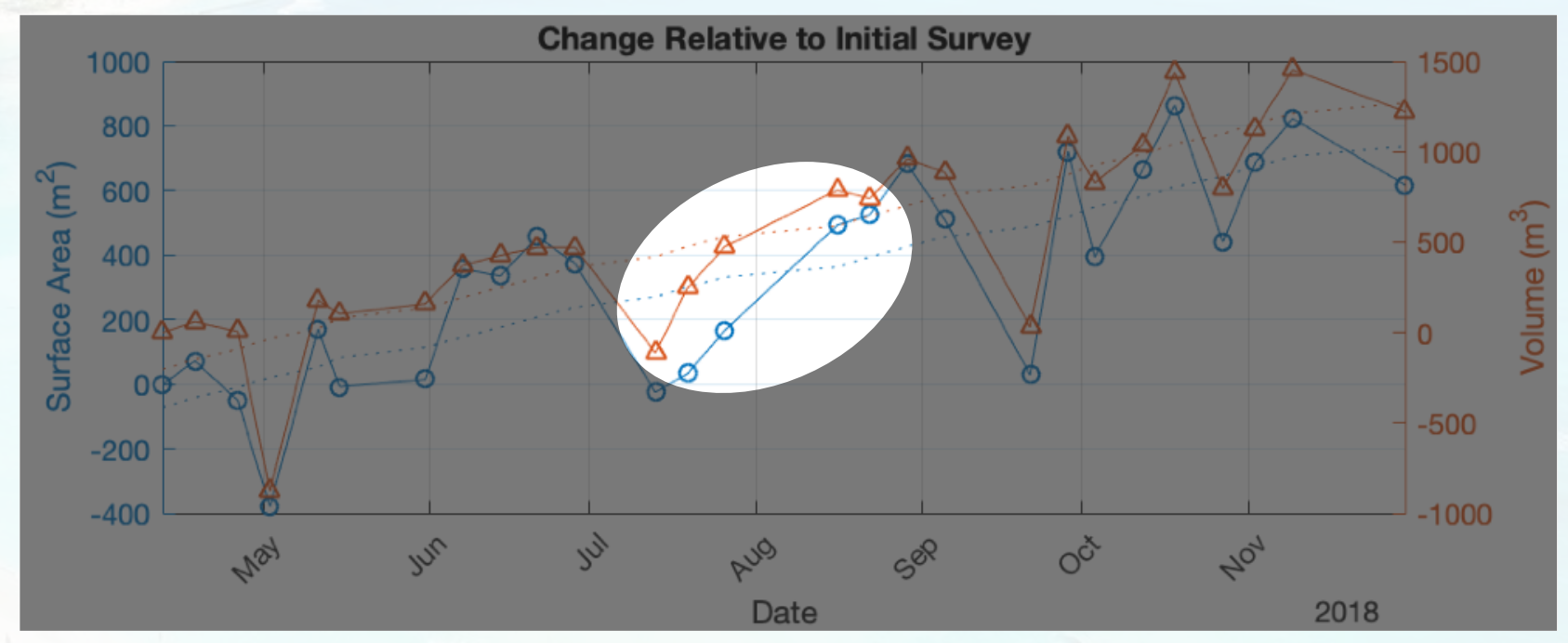



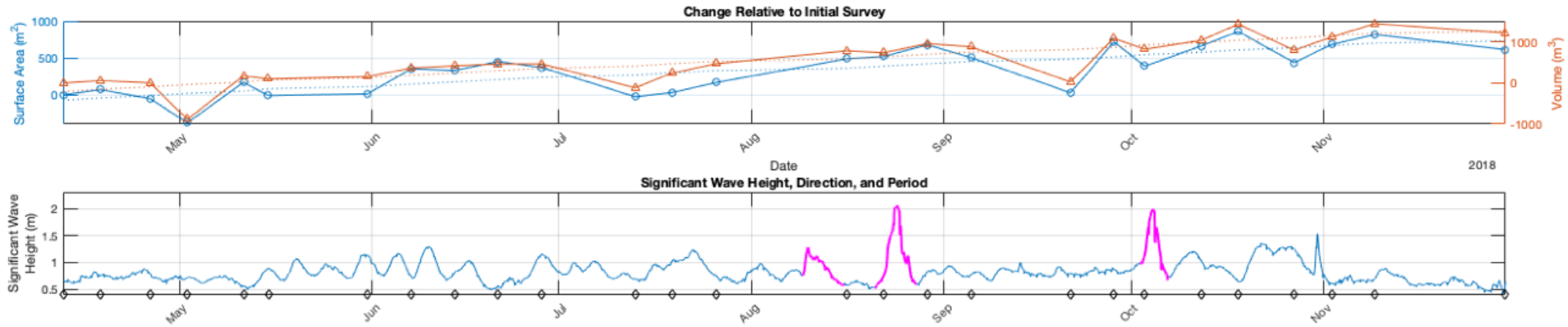

(1) (2) Wind Direction and Speed

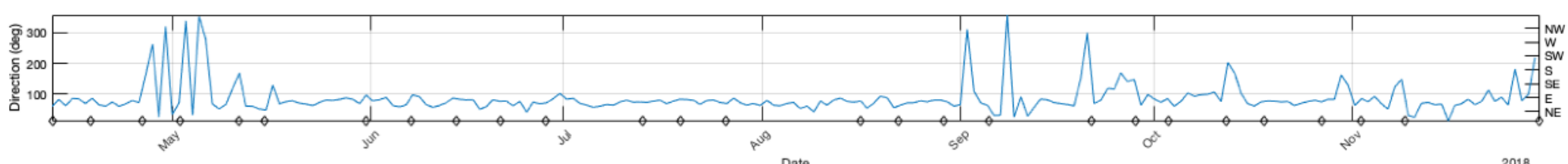


Surface

Area (m2)/

Volume (m3)
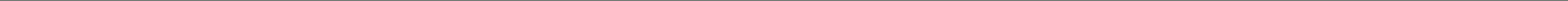

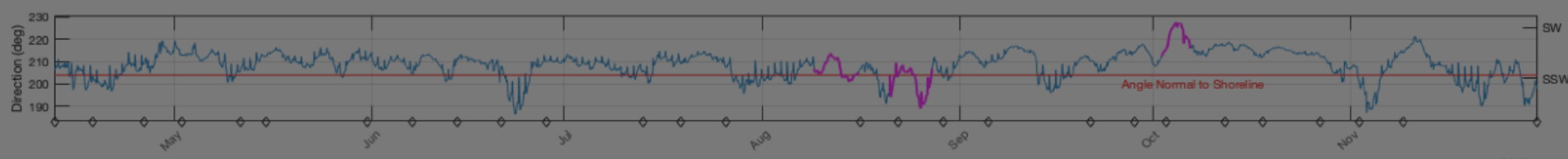

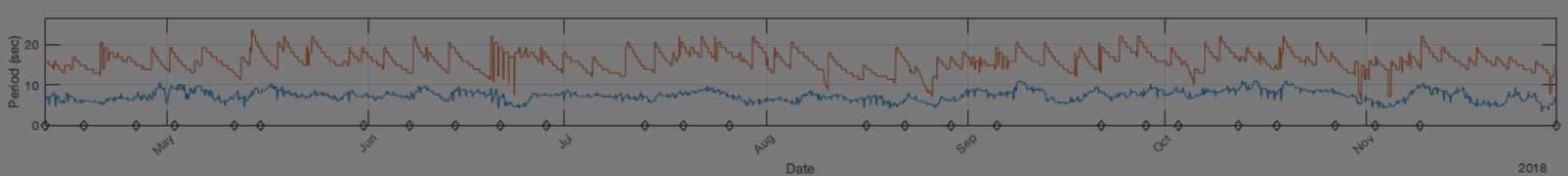

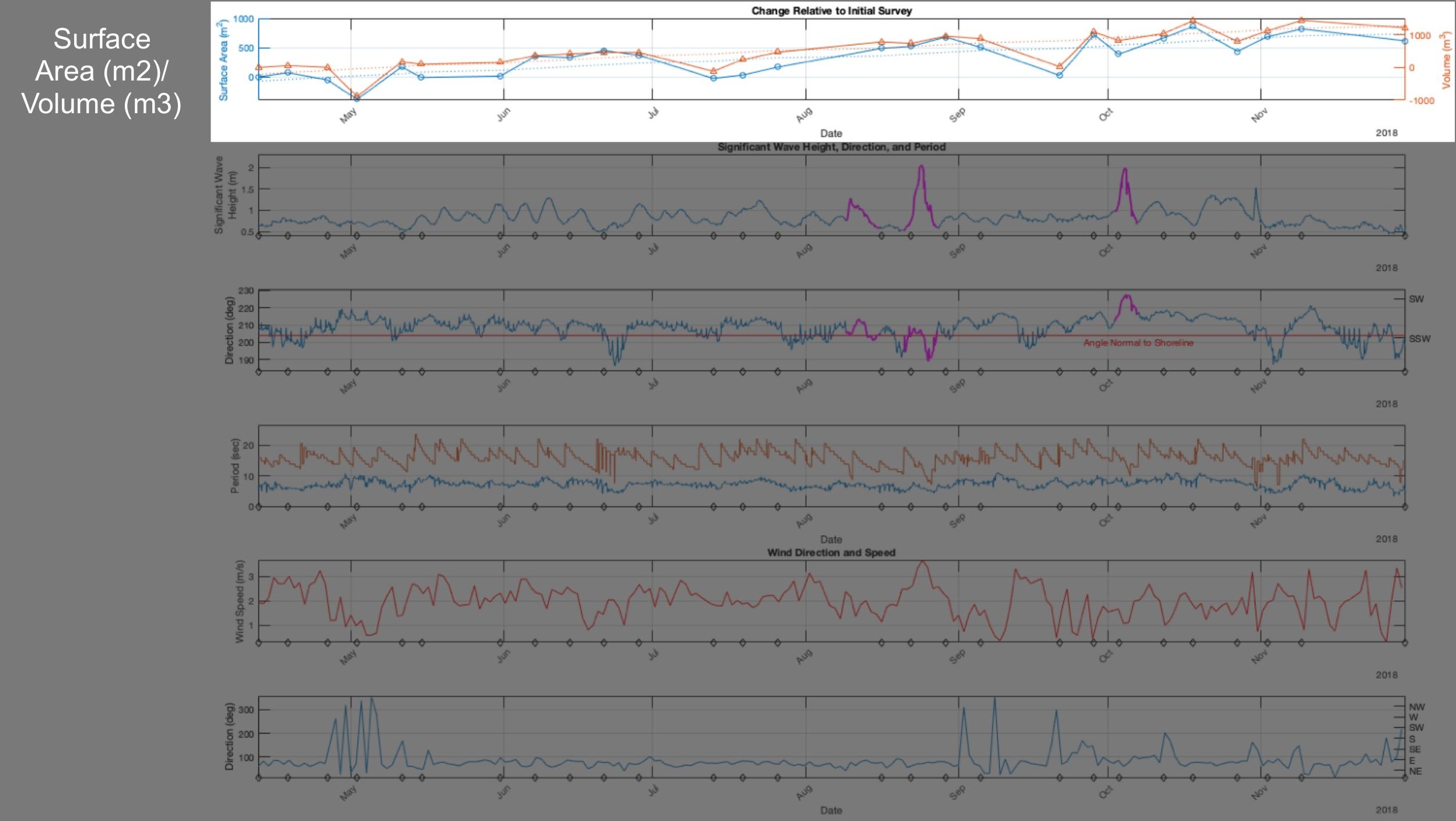

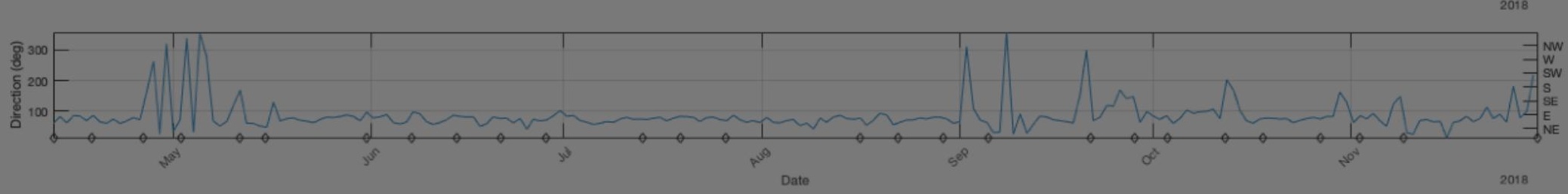



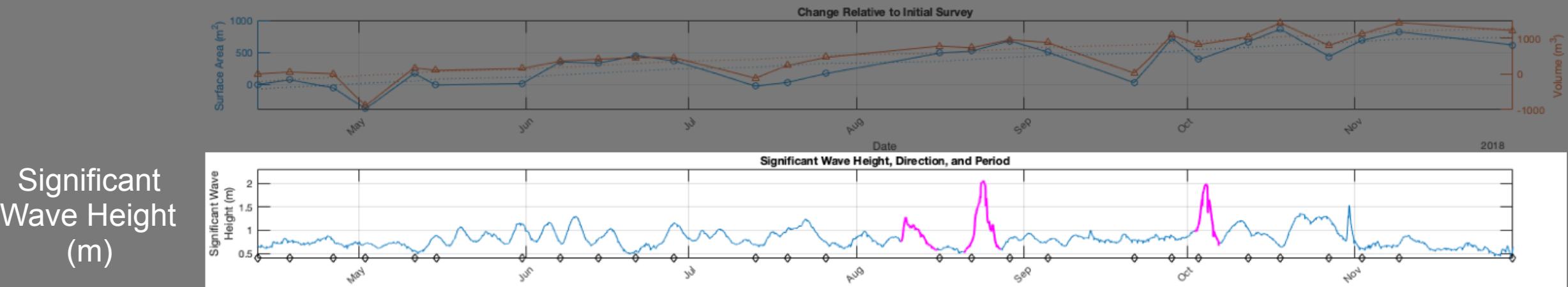

Direction (deg)

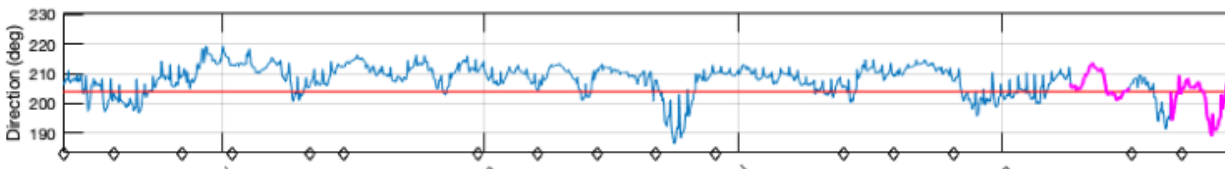

(2018

Period (sec)
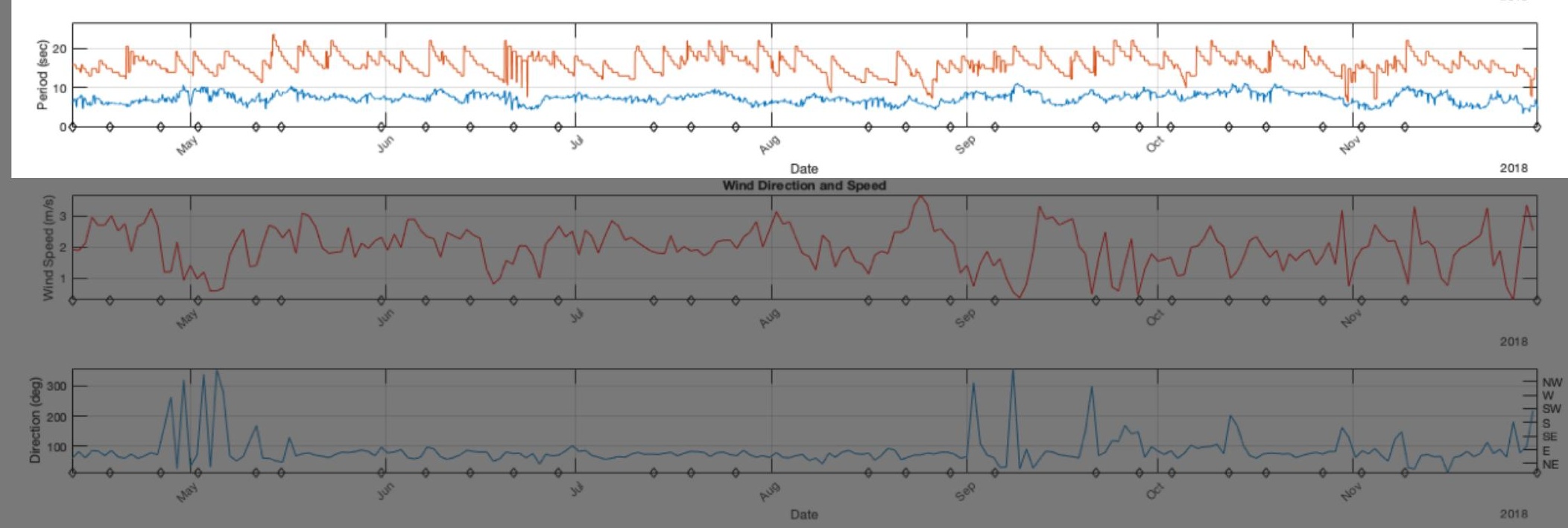

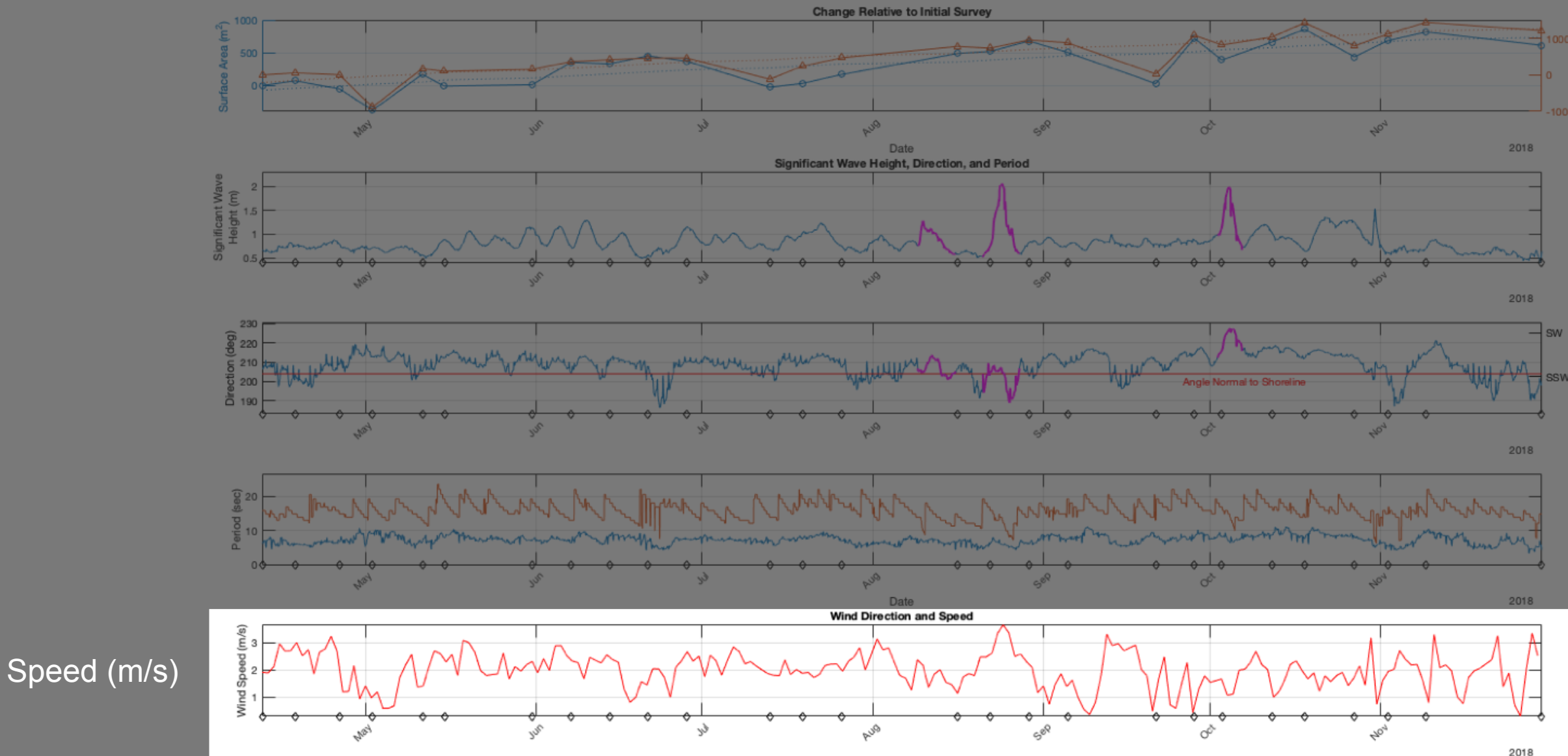

Direction (deg)
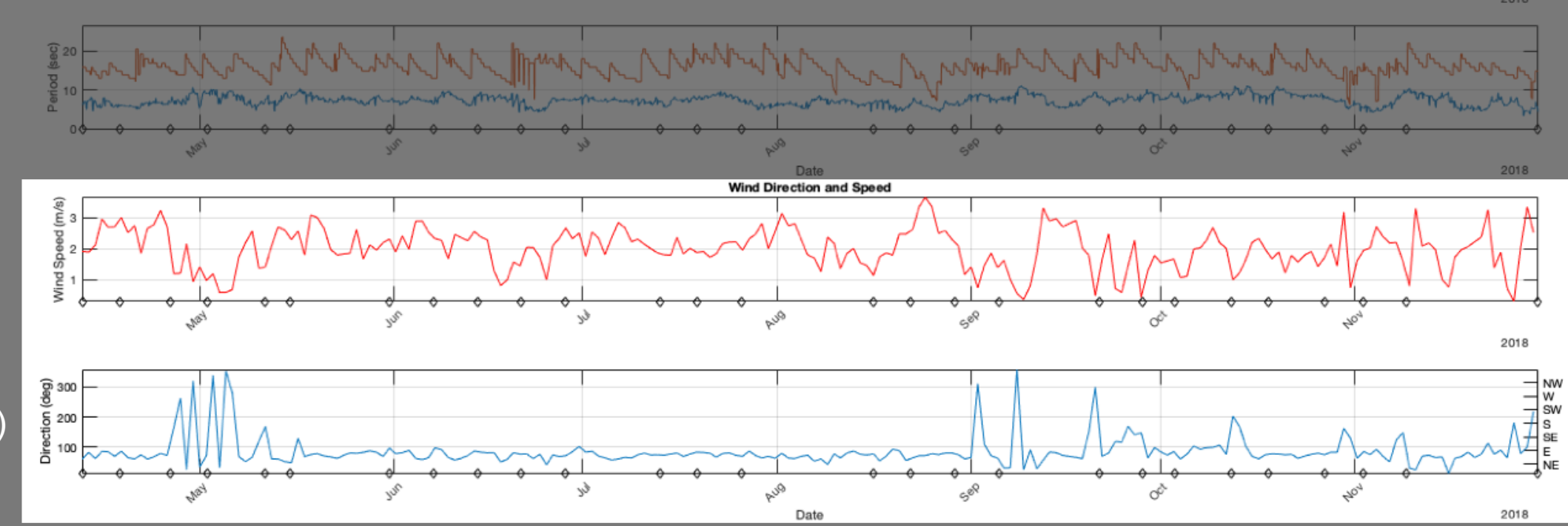
This erosion event seems to correlate with a weak south swell followed by more energetic SSW swells and a regular NE tradewind pattern
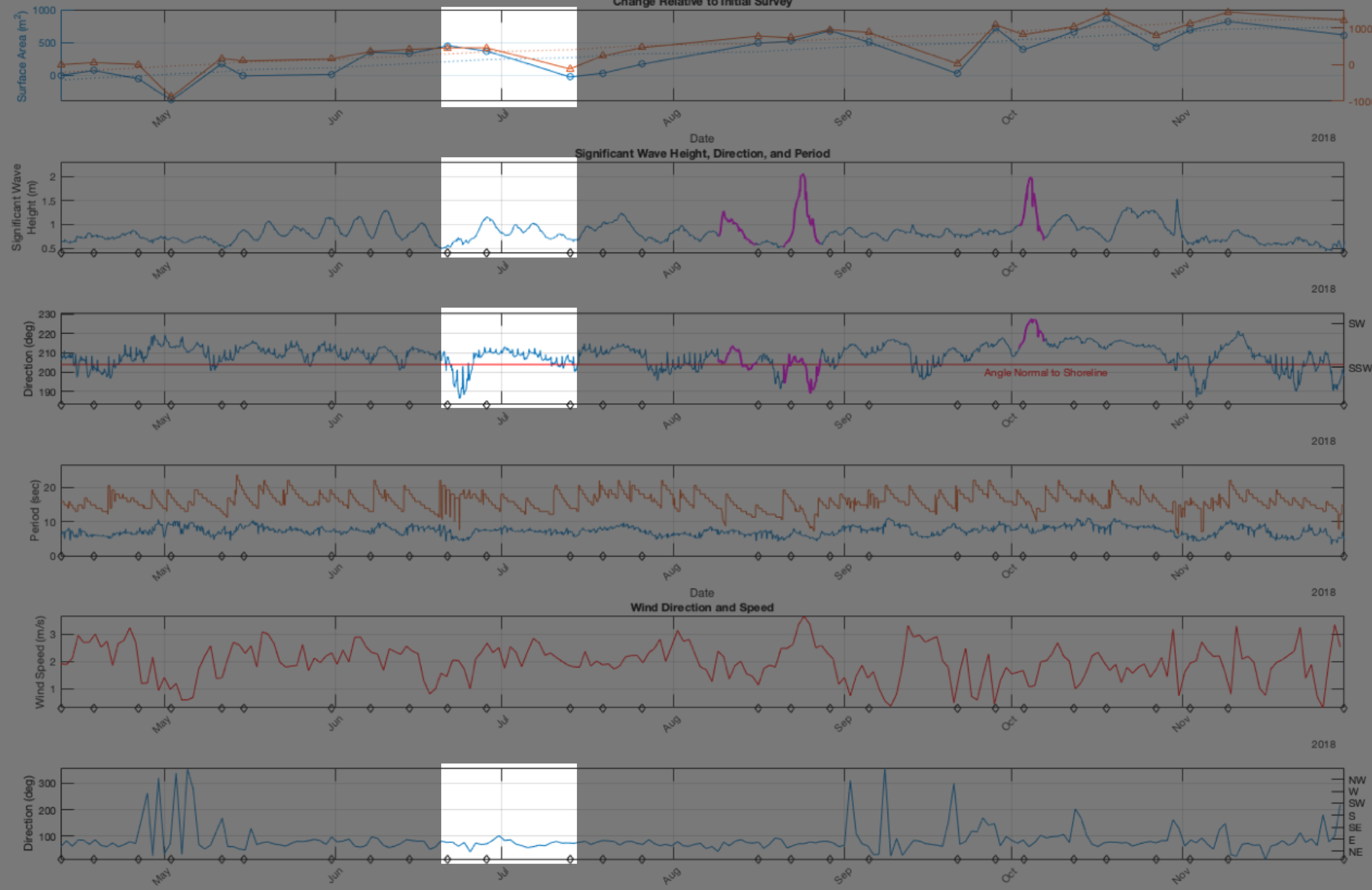
Wind Direction and Speed
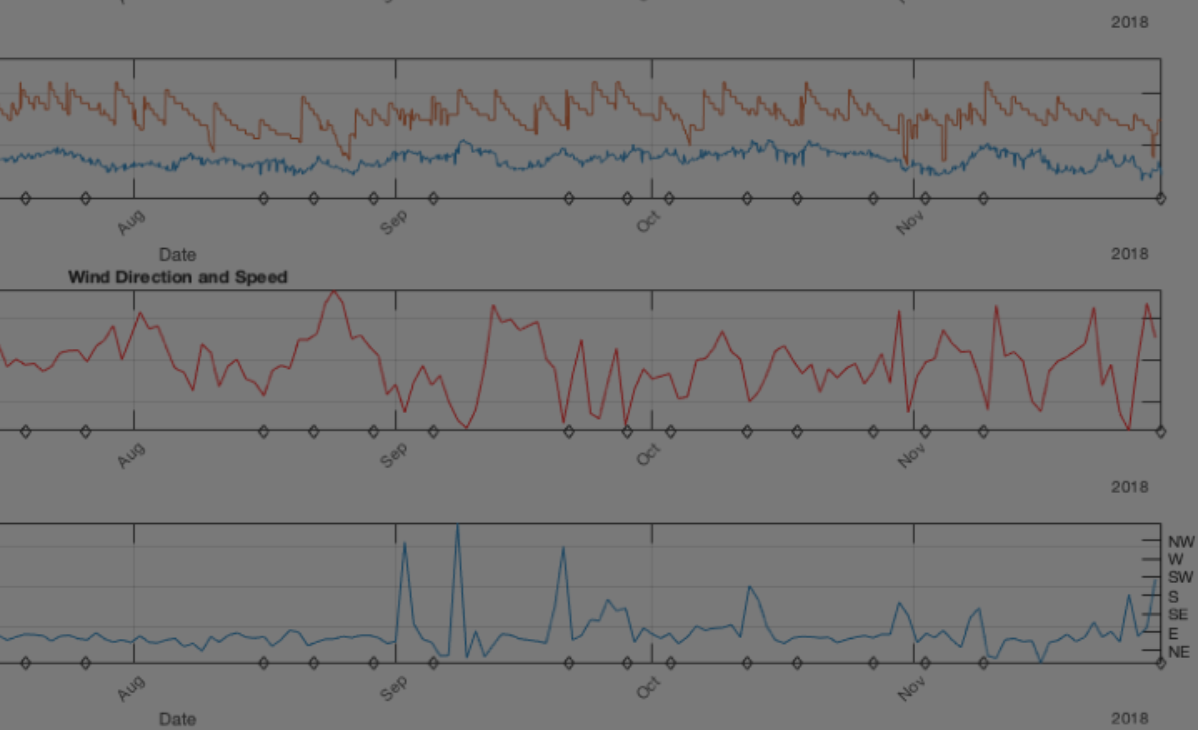
Hurricanes generating short period swell of varying directions along with typical tradewind patterns result in accretion
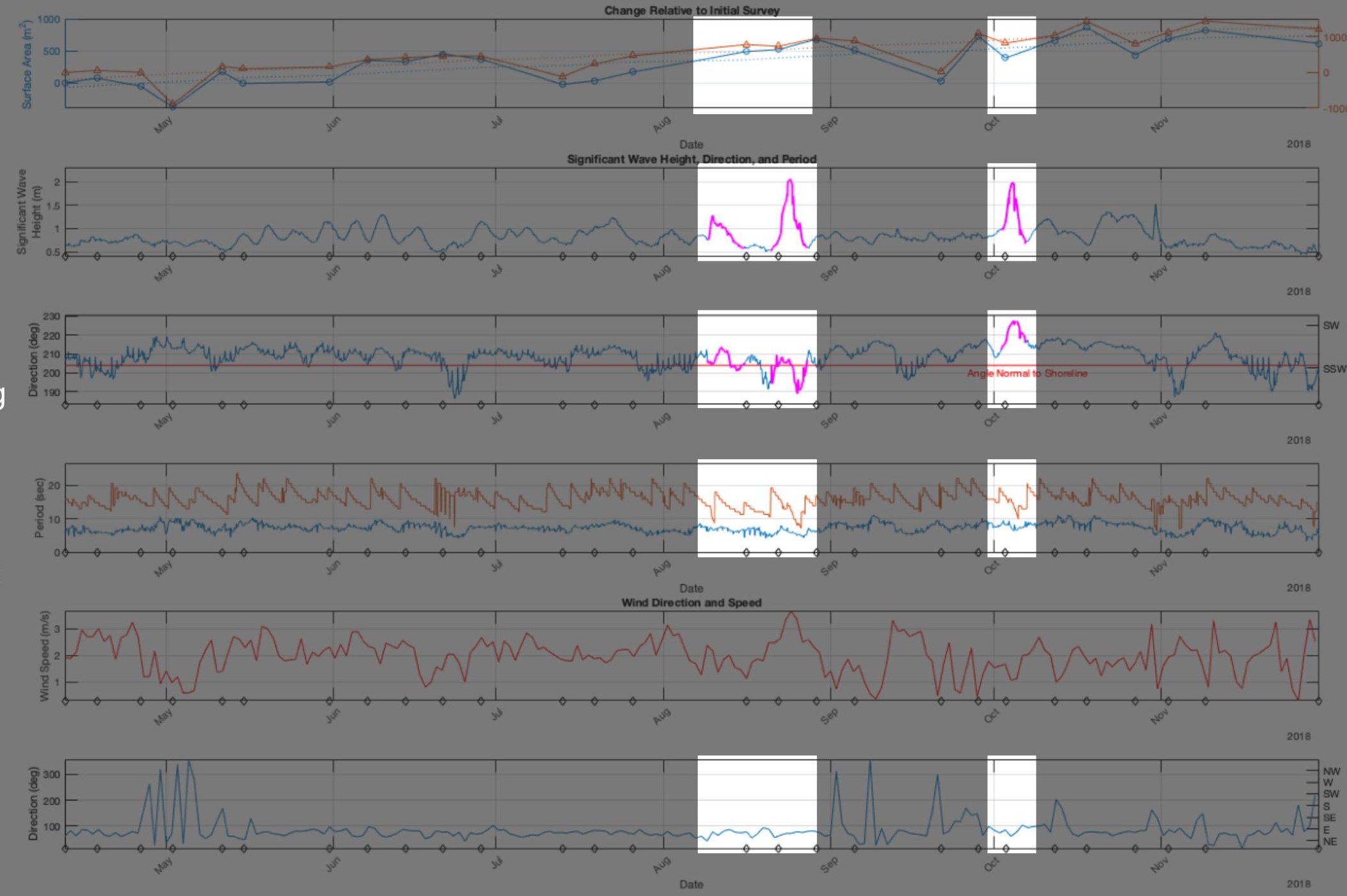


\section{Results \& Discussion}

- Empirical Orthogonal Function (EOF) analysis used for spatiotemporal data analysis of a single field (i.e. elevation)

- Useful where data representing a snapshot in time is linked to spatial dimensions (northing and easting, latitude and longitude, etc)

- Finds "spatial patterns of variability, their time variation, and gives a measure of the 'importance' of each pattern"

- These patterns can be correlated to specific wave conditions and events

- Gives insight into sediment transport mechanisms related to these conditions or events 


\section{Tandem}

Mode 1 (51\% variability): Congruent Transport, 2 Cells Closed system? Cross-shore exchange? 2 subcells

Directionality of sand transport is consistent in both cells
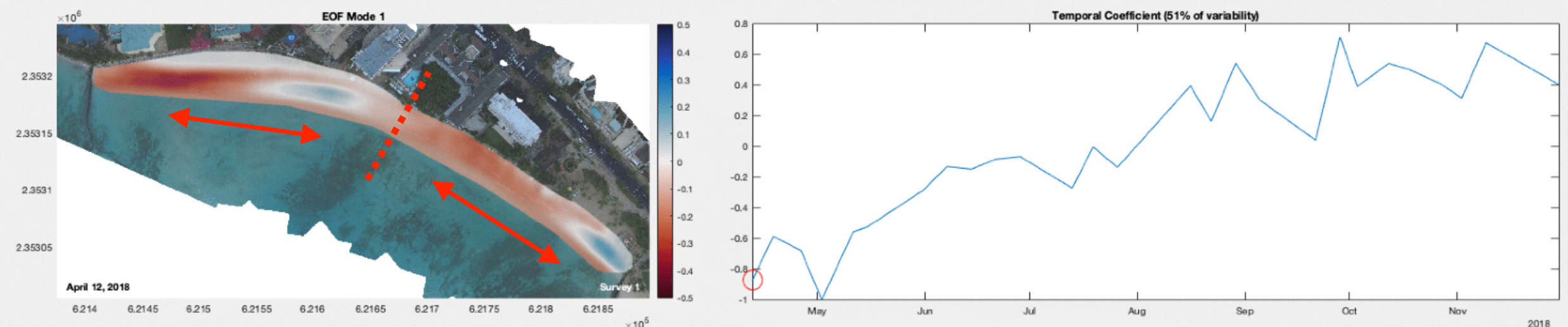
Mode 2 ( $12 \%$ variability): Non-congruent Transport, 2 cells

Open system, channel accretion? (Habel et al., 2012)

Again, 2 subcells within greater system

Directionality of sand transport is opposite in both cells

\section{Opposed}
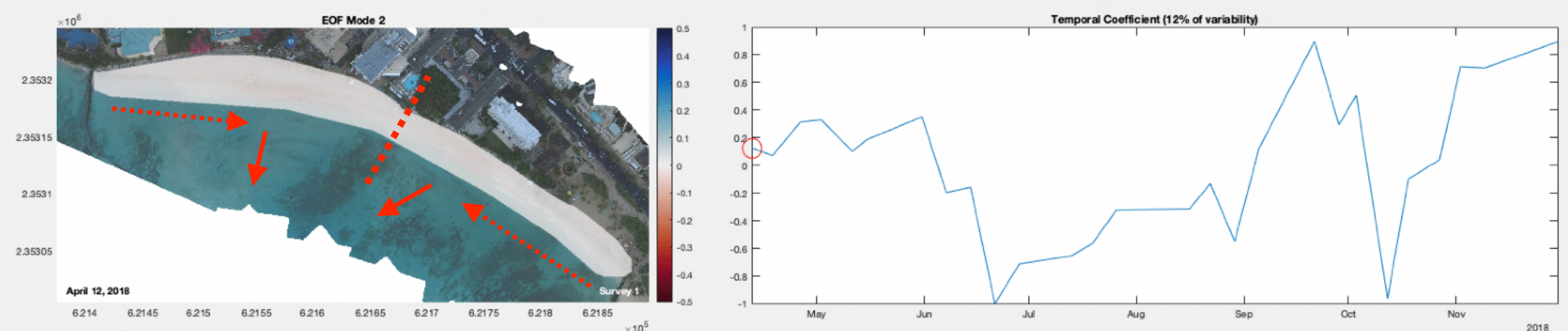


\section{Uncertainty}

- Currently engaged in uncertainty analysis

- Validating the accuracy of UAS generated point cloud/DEM

- Post-processed DTM vertical variation $<3 \mathrm{~cm}$

- Validating cross shore profile assumptions

- Interpolation area from seaward-most UAS generated point and toe measurement

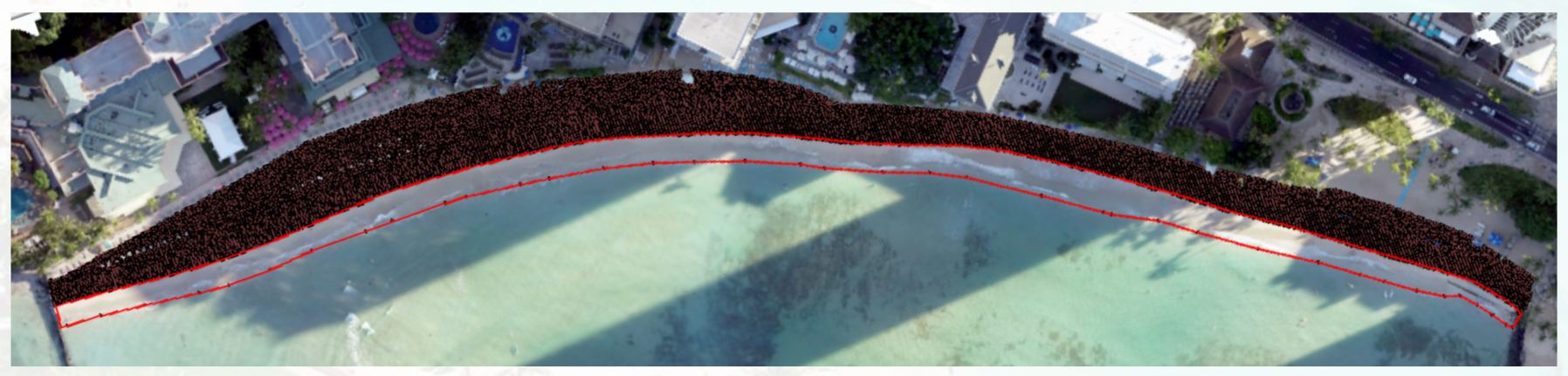




\section{Uncertainty}

- Currently engaged in uncertainty analysis

- Validating the accuracy of UAS generated point cloud/DEM

- Post-processed DTM vertical variation $<3 \mathrm{~cm}$

- Validating cross shore profile assumptions

- Interpolation area from seaward-most UAS generated point and toe measurement

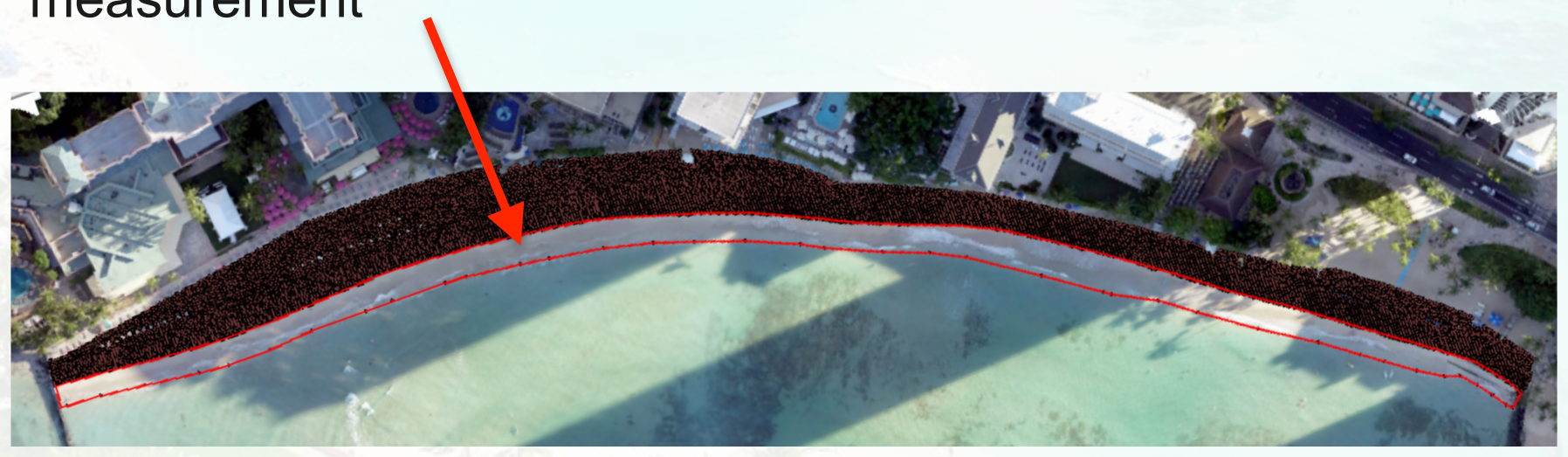




\section{Takeaways}

- Waikīkī Beach

- Overall increase in surface area and volume over study period

- Clear association between beach response and wind/waves

- West end of beach generally accretes, east end erodes

- Lack of offshore information a limitation

- UAS and Coastal Monitoring

- UAS capable of providing high-resolution, near-real time, actionable results

- Capture smaller scale beach dynamics

- Efficient - reduces hours in the field 


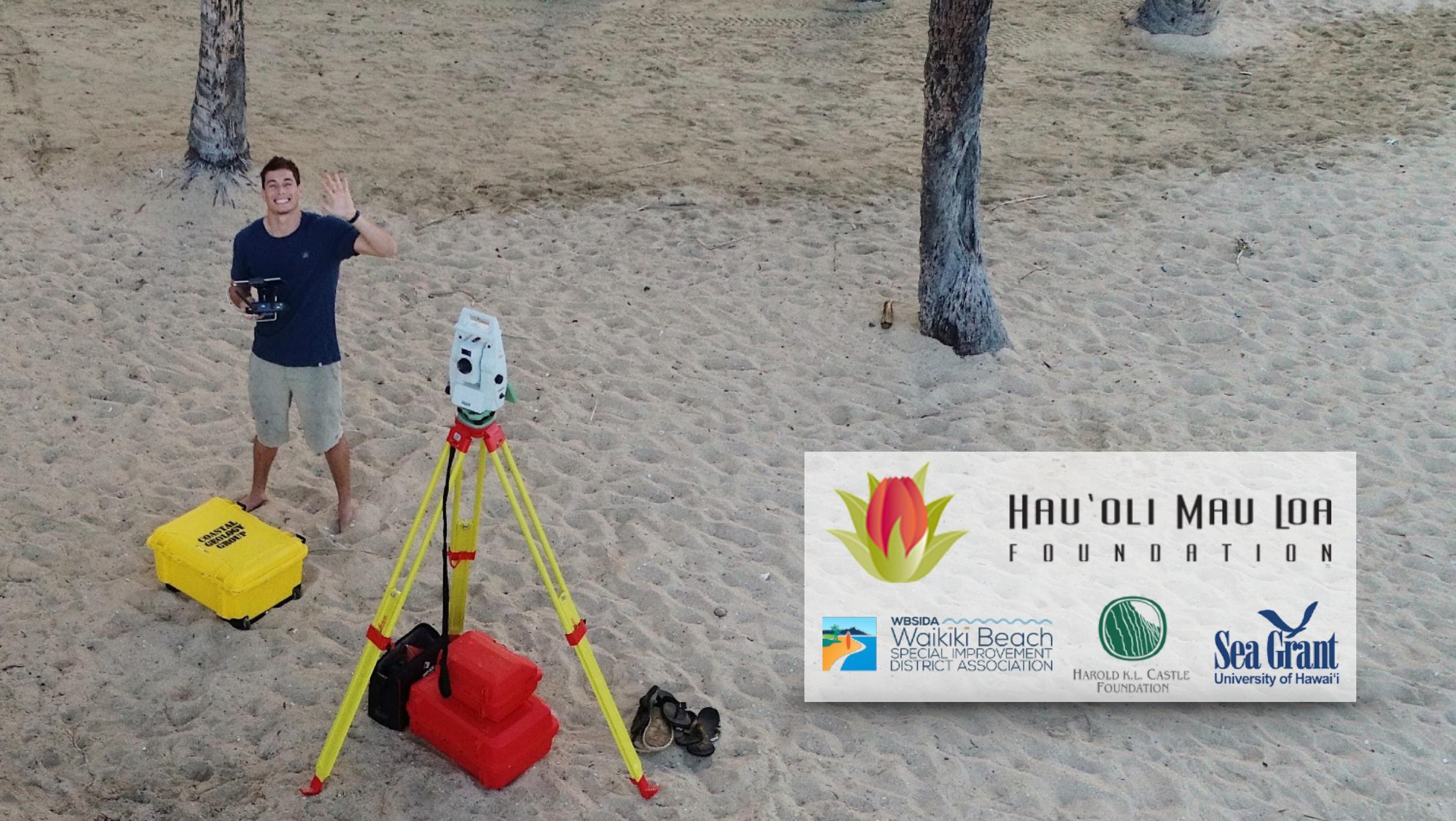


